\title{
Role of the ubiquitin-proteasome system in brain ischemia: Friend or foe?
}

\author{
Margarida V. Caldeira a,b,1 Ivan L. Salazar $^{\mathrm{a}, \mathrm{c}, \mathrm{d}, 1}$, Michele Curcio ${ }^{\mathrm{a}, \mathrm{e}, 1}$, \\ Lorella M.T. Canzoniero $^{e}$, Carlos B. Duarte ${ }^{a, b, *}$ \\ ${ }^{a}$ CNC-Center for Neuroscience and Cell Biology, University of Coimbra, Largo Marquês de Pombal, 3004-517 Coimbra, Portugal \\ ${ }^{\mathrm{b}}$ Department of Life Sciences, University of Coimbra, 3004-517 Coimbra, Portugal \\ ${ }^{\mathrm{c}}$ Doctoral Programme in Experimental Biology and Biomedicine, Center for Neuroscience and Cell Biology, University of Coimbra, Portugal \\ ${ }^{\mathrm{d}}$ Institute for Interdisciplinary Research, University of Coimbra (IIIUC), Portugal \\ e Department of Science and Technology, University of Sannio, Benevento, Italy
}

\section{A R T I C L E I N F O}

\section{Article history:}

Received 14 June 2013

Received in revised form 8 October 2013

Accepted 15 October 2013

Available online 22 October 2013

\section{Keywords:}

Ubiquitin-proteasome system

Brain ischemia

Excitotoxicity

Proteasome inhibitors

\begin{abstract}
A B S T R A C T
The ubiquitin-proteasome system (UPS) is a catalytic machinery that targets numerous cellular proteins for degradation, thus being essential to control a wide range of basic cellular processes and cell survival. Degradation of intracellular proteins via the UPS is a tightly regulated process initiated by tagging a target protein with a specific ubiquitin chain. Neurons are particularly vulnerable to any change in protein composition, and therefore the UPS is a key regulator of neuronal physiology. Alterations in UPS activity may induce pathological responses, ultimately leading to neuronal cell death. Brain ischemia triggers a complex series of biochemical and molecular mechanisms, such as an inflammatory response, an exacerbated production of misfolded and oxidized proteins, due to oxidative stress, and the breakdown of cellular integrity mainly mediated by excitotoxic glutamatergic signaling. Brain ischemia also damages protein degradation pathways which, together with the overproduction of damaged proteins and consequent upregulation of ubiquitin-conjugated proteins, contribute to the accumulation of ubiquitincontaining proteinaceous deposits. Despite recent advances, the factors leading to deposition of such aggregates after cerebral ischemic injury remain poorly understood. This review discusses the current knowledge on the role of the UPS in brain function and the molecular mechanisms contributing to UPS dysfunction in brain ischemia with consequent accumulation of ubiquitin-containing proteins. Chemical inhibitors of the proteasome and small molecule inhibitors of deubiquitinating enzymes, which promote the degradation of proteins by the proteasome, were both shown to provide neuroprotection in brain ischemia, and this apparent contradiction is also discussed in this review.
\end{abstract}

() 2013 Elsevier Ltd. All rights reserved.

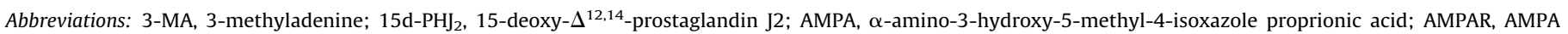

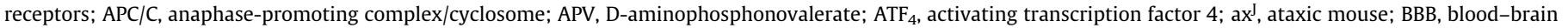

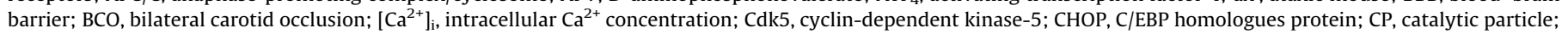

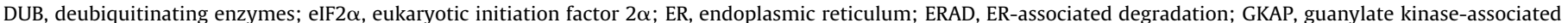

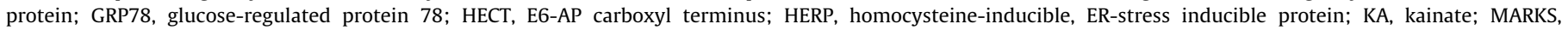

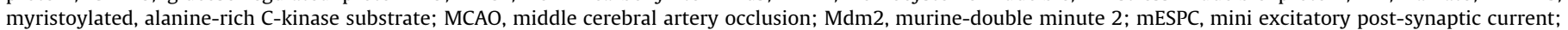

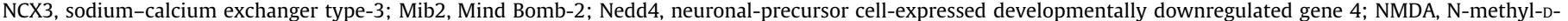

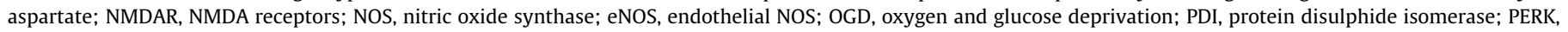

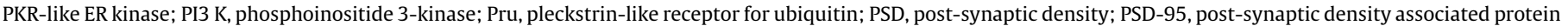

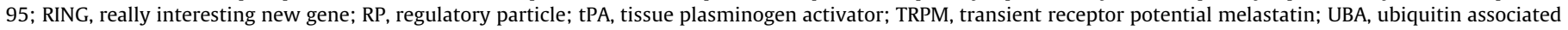

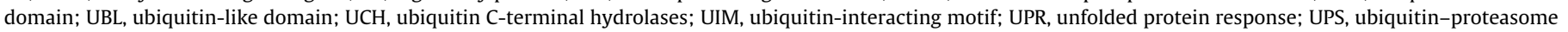
system; USP, ubiquitin specific protease; VGLUT, vesicular glutamate transporters; XBP1, X-box binding protein 1.

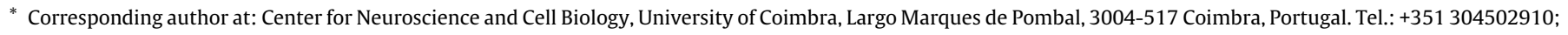
fax: +351239822 776 .

E-mail address: cbduarte@ci.uc.pt (C.B. Duarte).

1 These authors contributed equally to this work. 
Contents

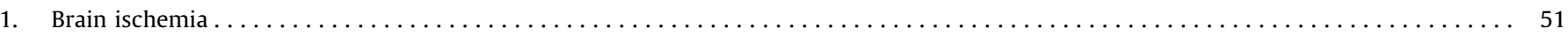

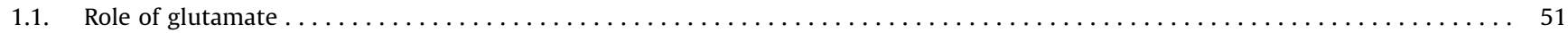

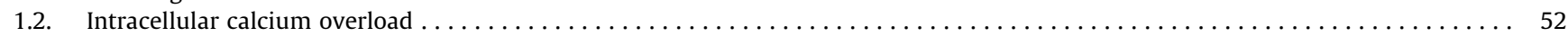

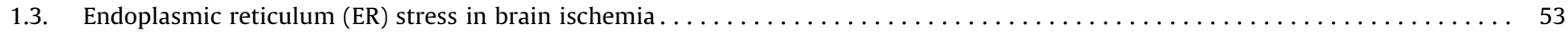

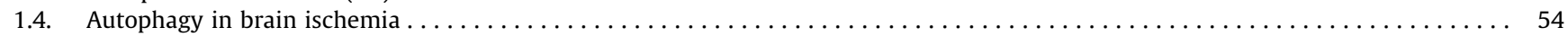

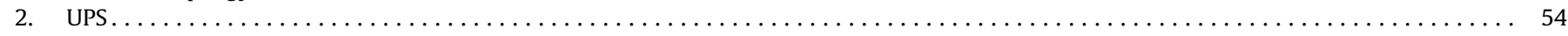

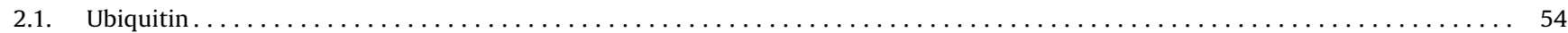

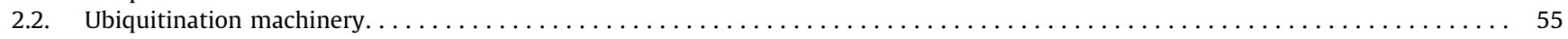

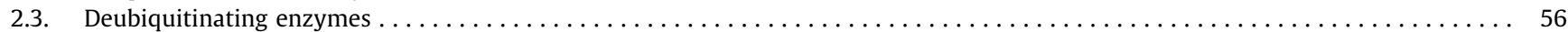

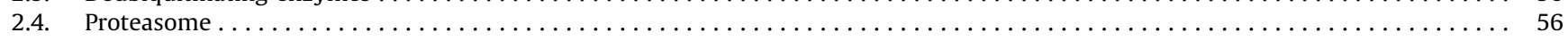

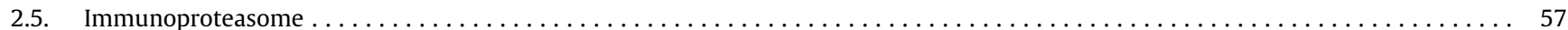

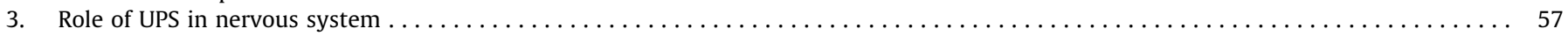

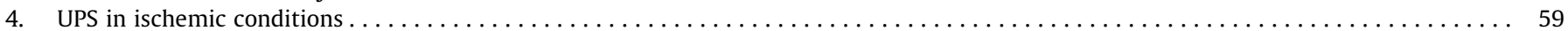

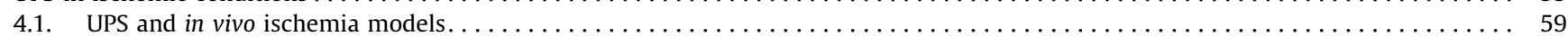

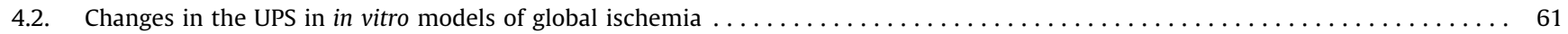

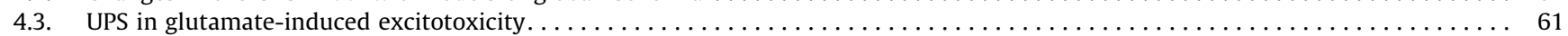

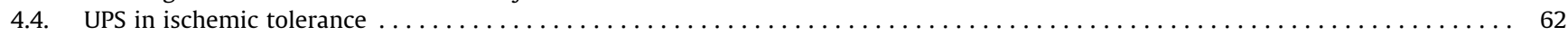

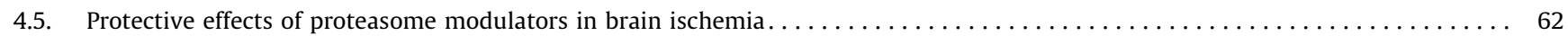

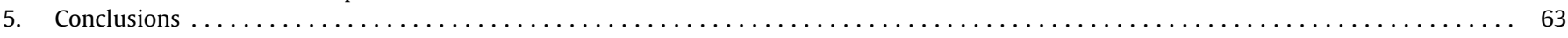

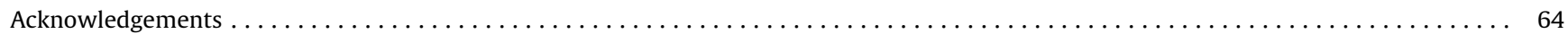

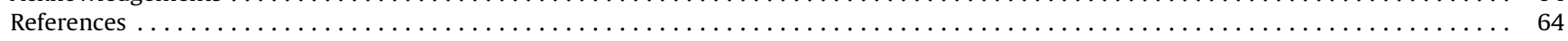

\section{Brain ischemia}

Brain ischemia is a leading cause of death and disability worldwide, resulting from a reduction in the blood flow to the brain. This leads to a deprivation of oxygen and glucose, and cell death is the fatal end caused by the reduction of the fuels available for the metabolism of the cells. Brain ischemia may be caused by cardiac arrest (global ischemia, affecting the entire brain) or by ischemic stroke (focal ischemia, which targets a specific brain region).

Ischemic stroke occurs as a result of the occlusion of a blood vessel supplying blood to the brain by a thrombus or an embolus (Doyle et al., 2008; Roger et al., 2012). In this condition, the region of the brain that is most damaged, the ischemic core, fully depends on oxygen and glucose provided by the affected blood vessel, while the penumbra region, the area surrounding the infarcted core, is not as compromised due to a limited supply of components required for the metabolism derived from the collateral circulation. Glucose is the main substrate for cerebral energy production (Hofmeijer and van Putten, 2012) and during stroke the oxygen carried by the blood is much less than that required for complete oxidation of its content of glucose. Under these conditions, glycolysis may persist after oxygen has been depleted, but the reduction of oxidative metabolism of glucose leads to decreased ATP levels, while ADP and AMP levels increase (Hertz, 2008), causing a disruption of ionic homeostasis (Hansen, 1985), opening of anion channels (Kimelberg and Mongin, 1998), plasma membrane depolarization (Lipton, 1999), release of glutamate through astrocytic hemichannels (Ye et al., 2003) and downregulation of glutamate transporters (Harvey et al., 2011). The impairment of glutamate transporters, in addition to their operation in the reverse mode, leads to an accumulation of glutamate in the extracellular space (Grewer et al., 2008) and a consequent overactivation of postsynaptic glutamate receptors. Under these conditions, necrotic cell death occurs at the core region, while in the penumbra region the availability of ATP allows a delayed cell death by apoptosis (Broughton et al., 2009).

The hippocampus is particularly vulnerable to brain ischemia, but distinct responses are typically observed in the different hippocampal subregions. The CA1 region is highly sensitive to transient ischemia followed by reperfusion, but this neuronal population die far later after ischemic insult, a process referred to as delayed neuronal death (Kirino, 1982; Pulsinelli et al., 1982a). This is a unique type of cell death that progresses despite complete recovery of metabolic parameters, such as regional blood flow, glucose metabolism and tissue ATP content (Kirino, 1982; Pulsinelli et al., 1982b; Mies et al., 1990), but the molecular mechanisms involved are yet to be clearly understood.

\subsection{Role of glutamate}

During stroke, membrane depolarization due to ATP breakdown leads to an increase in the release of glutamate, and the lack of energy blocks the reuptake of the excitatory amino acids at the synapse, leading to an extracellular accumulation of glutamate (Rossi et al., 2000; Grewer et al., 2008). The reversal of the glutamate transporters under these conditions (Rossi et al., 2000; Grewer et al., 2008) further contributes to the extracellular accumulation of glutamate, with a consequent toxic overactivation of postsynaptic glutamate receptors (excitotoxicity) (Olney, 1969; Simon et al., 1984; Choi et al., 1987; Ferreira et al., 1996, 1998; Martel et al., 2012). Upon oxygen and glucose deprivation (OGD), a well established in vitro model of global ischemia, glutamate is massively released by neurons, and the resulting increase in the intracellular $\mathrm{Ca}^{2+}$ concentration $\left(\left[\mathrm{Ca}^{2+}\right]_{\mathrm{i}}\right)($ Goldberg and Choi, 1993) causes a delayed neuronal cell death (calcium overload hypothesis) (Manev et al., 1989). $\mathrm{Ca}^{2+}$ uptake and neuronal cell death can be prevented by the NMDA (N-methyl-D-aspartate) receptor (NMDAR) antagonist D-aminophosphonovalerate (APV) (Goldberg and Choi, 1993). In addition, the volume of microinfarcts induced by occlusions of individual penetrating arterioles or venules in the rat brain cortex could be reduced by administrating memantine 30-45 min after the occlusion, ameliorating perceptual deficits (Shih et al., 2013). These data indicate that NMDAR, characterized by their high $\mathrm{Ca}^{2+}$ permeability, are the link between glutamate, $\mathrm{Ca}^{2+}$ and neuronal cell death. On the other hand, it was shown that blocking NMDAR with MK-801 decreases the density of healthy cells in the dentate gyrus (Gould et al., 1994), indicating that a moderate flow of $\mathrm{Ca}^{2+}$ ions through NMDAR is beneficial for neurons, while $\mathrm{Ca}^{2+}$ overload, linked with an excessive NMDAR 
activation, is deleterious (NMDAR paradox) (Hardingham and Bading, 2003).

Not all NMDAR contribute to neuronal cell death in excitotoxicity, since the synaptic and extrasynaptic receptor populations are differentially coupled to the activation of intracellular signaling mechanisms: the latter receptors mediate the influx of calcium ions leading to mitochondrial injury (Stanika et al., 2009), activation of pro-apoptotic genes (Leveille et al., 2010), cleavage of fodrin and the sodium-calcium exchanger type-3 (NCX3) by calpains (Xu et al., 2009a), and cell death (Hardingham et al., 2002). On the other hand, activation of synaptic NMDAR is not coupled to hippocampal neuron damage (Hardingham et al., 2002), but rather promotes resistance to oxidative insults and prevents accumulation of reactive oxygen species in cortical neurons (Papadia et al., 2008) (Fig. 1). Furthermore, synaptic NMDA receptors induce genomic alterations that render neurons more resistant to apoptosis and oxidative insults (Hardingham et al., 2002; Leveille et al., 2010; Kaufman et al., 2012; Karpova et al., 2013). However, the relative role of synaptic and extrasynaptic NMDAR in excitotoxic cell death needs further investigation, considering the conflicting results showing neurotoxicity induced by synaptic NMDAR (Papouin et al., 2012) and the evidence pointing to a role for these receptors in hypoxic excitotoxic death (Wroge et al., 2012).

In addition to the role played by NMDAR in neuronal death in brain ischemia, AMPA ( $\alpha$-amino-3-hydroxy-5-methyl-4-isoxazole proprionic acid) receptor (AMPAR) activity was also shown to mediate ischemic stroke damage in hippocampal CA1 pyramidal neurons (Soundarapandian et al., 2005). Exposure of hippocampal neurons to a brief period of OGD promotes a redistribution of AMPAR at the synapse, with internalization of synaptic GluA2containing AMPAR and synaptic delivery of AMPAR lacking GluA2 subunits, which are permeable to calcium and zinc (Liu et al., 2006). In fact, activation of AMPAR was also shown to induce calpain activation (Araujo et al., 2004), and AMPAR antagonists provided neuroprotection in a model of in vivo ischemia (Sheardown et al., 1990; Noh et al., 2005). Taken together, these data indicate that NMDAR may act together with AMPAR to induce neuronal demise under excitotoxic conditions.

\subsection{Intracellular calcium overload}

The perfect gear that regulates $\mathrm{Ca}^{2+}$ efflux, intracellular $\mathrm{Ca}^{2+}$ buffering and intracellular $\mathrm{Ca}^{2+}$ storage is a neuronal feature that maintains a low intracellular calcium concentration $\left(\left[\mathrm{Ca}^{2+}\right]_{i}\right)$ when compared with the extracellular space (Sattler and Tymianski, 2000). Following ischemia, the $\left[\mathrm{Ca}^{2+}\right]_{i}$ can reach $\mu \mathrm{M}$ levels due to the breakdown of these mechanisms and the intracellular calcium overload is linked with overactivation of enzymes such as proteases, phospholipases and endonucleases, with the resulting breakdown of proteins, lipids and nucleic acids, and consequent neuronal death (Coyle and Puttfarcken, 1993; Lee et al., 1999). Calpains are a group of $\mathrm{Ca}^{2+}$-dependent proteases very well characterized for their role in neurodegeneration. The excessive

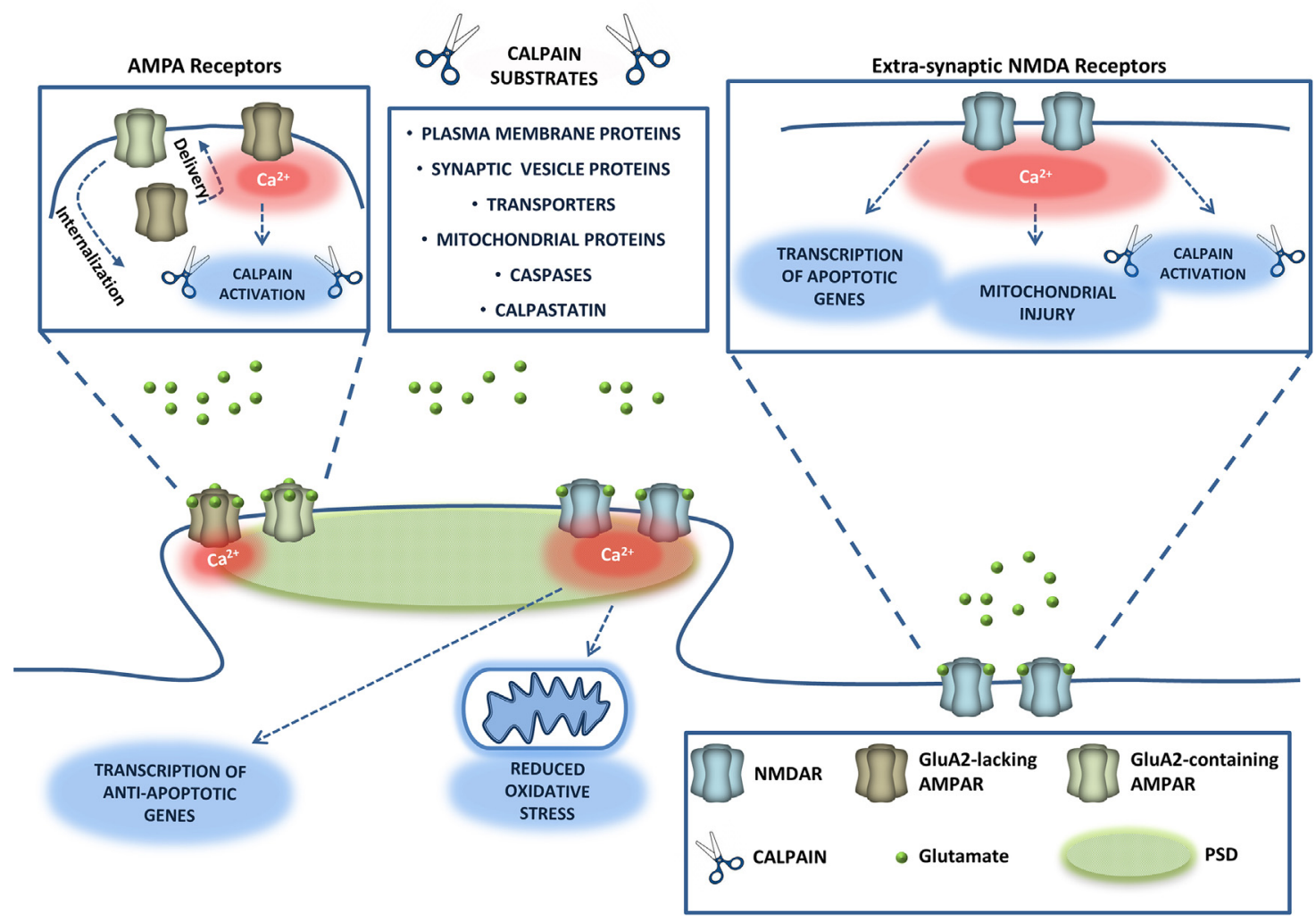

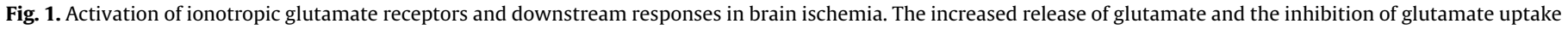

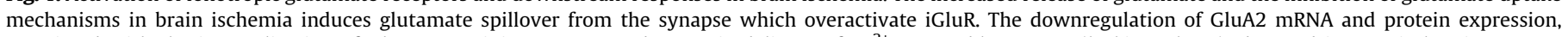

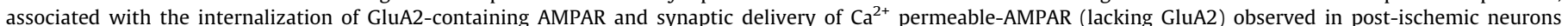

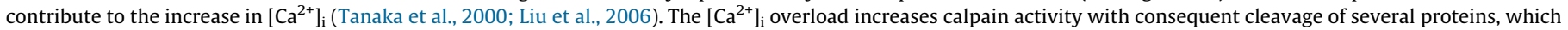

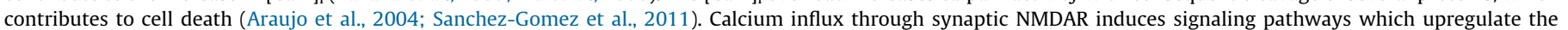

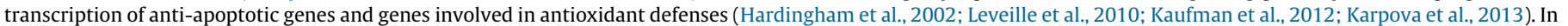

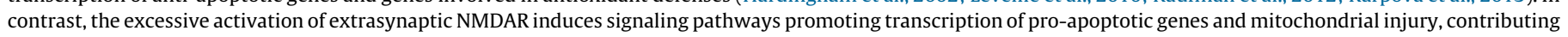

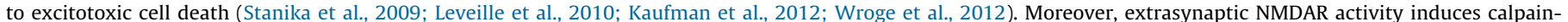

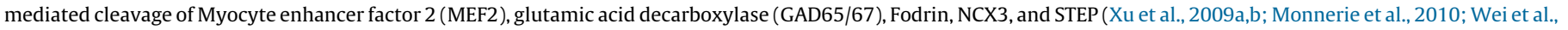
2012). 
activation of calpains by the intracellular calcium overload in brain ischemia and in excitotoxic conditions (Camins et al., 2006; Bevers and Neumar, 2008) leads to the cleavage of plasma membrane proteins (Lu et al., 2000; Neumar et al., 2001; Rong et al., 2001; Yuen et al., 2007; Gomes et al., 2012), synaptic vesicle proteins (Gomes et al., 2011; Lobo et al., 2011), transporters (Bano et al., 2005; Pottorf et al., 2006), mitochondrial proteins (Takano et al., 2005) and many other substrates (Bevers and Neumar, 2008). Lipases are also activated by calcium, further increasing the production of free radical species (Farooqui and Horrocks, 1994). The neuronal isoform of nitric oxide synthase (NOS) is also activated by $\mathrm{Ca}^{2+}$ and ischemia-associated $\mathrm{NO}$ overproduction perturbs ATP synthesis and induces the release of proteins involved in cell death (Heales et al., 1999).

Besides the glutamate receptor-induced $\left[\mathrm{Ca}^{2+}\right]_{i}$ overload (see above), other channels have been proposed to mediate $\mathrm{Ca}^{2+}$ influx under excitotoxic conditions. The activation of transient receptor potential melastatin (TRPM) channels, primarily the $\mathrm{Ca}^{2+}$-permeable TRPM2 (Lipski et al., 2006; Jia et al., 2011) and TRPM7 channels (Aarts et al., 2003; Sun et al., 2009), has been associated to oxidative stress, in addition to anoxic and ischemic cell death. Another key event during stroke is acidosis, caused by the decrease in the supply of oxygen to the brain, which leads to calcium influx, and failure of oxidative phosphorylation, with an increase in lactate production and the switch to glycolytic metabolism, with the final decrease in tissue pH (Xiong et al., 2004; Gu et al., 2010).

\subsection{Endoplasmic reticulum (ER) stress in brain ischemia}

Electron microscopy analysis of the ER and Golgi morphology showed significant alterations following brain ischemia and reperfusion, from 'flattened pancake' to 'rounded vesicles' (Petito and Pulsinelli, 1984). From the functional point of view, brain ischemia was shown to impair the sarcoplasmic/endoplasmic reticulum $\mathrm{Ca}^{2+}$ ATPase, which is responsible for the accumulation of $\mathrm{Ca}^{2+}$ into the ER (Kohno et al., 1997; Parsons et al., 1997, 1999). The resulting depletion of $\mathrm{Ca}^{2+}$ in this compartment is known to induce ER stress (e.g. Nakagawa et al., 2000). Pretreament with a NO synthase inhibitor significantly reduced the depletion of $\mathrm{Ca}^{2+}$ from the ER in gerbils subjected to transient global cerebral ischemia, suggesting that the increase in NO production during the early reperfusion period contributes to the loss in the $\mathrm{Ca}^{2+}$ buffering capacity of the ER (Kohno et al., 1997). Oxidative damage of the ER during the reperfusion period is also likely to contribute to the ER stress due to modifications induced in ER proteins (Hayashi et al., 2003).

Under mild ER stress conditions the cells develop a protective mechanism, named unfolded protein response (UPR), which is mediated by induction of molecular chaperones in the ER, downregulation of translation activity and enhancement of ERassociated degradation pathways (ERAD). However, more aggressive conditions upregulate the expression of proaptoptotic factors, including CHOP (C/EBP homologues protein)/GADD153, a member of the C/EBP family of transcription factors, and caspase-12, leading to cell death (Feng et al., 2001; DeGracia and Montie, 2004; Paschen and Mengesdorf, 2005; Boyce and Yuan, 2006).

Inhibition of translation in response to ER stress avoids the synthesis of proteins that could not be properly folded and, therefore, is thought to be protective. Translation inhibition in transient cerebral ischemia correlates with the selective vulnerability of post-ischemic neurons, and may be partly due to a transient activation of PKR-like ER kinase (PERK). This kinase phosphorylates the eIF2 $\alpha$ (eukaryotic initiation factor $2 \alpha$ ) thereby inhibiting the initiation step of protein synthesis (Kumar et al., 2001, 2003; Hayashi et al., 2003, 2004; Paschen et al., 2003; Nakka et al., 2010). However, additional mechanisms may also contribute to the inhibition of protein synthesis after transient brain ischemia (for more detailed discussion see: DeGracia and Montie, 2004; DeGracia et al., 2008). mRNAs whose translation is normally blocked by $5^{\prime}$ upstream open-reading frames can still be translated in the presence of the phosphorylated form of eIF $2 \alpha$ (eukaryotic initiation factor $2 \alpha$ ) and this may explain the synthesis of specific proteins in UPR. The mRNA coding for ATF4 (activating transcription factor 4 ) is translated by this mechanism (Harding et al., 2000), and the ATF4 transcription factor is known to contribute to chop mRNA transcription (Ma et al., 2002). An upregulation of the chop mRNA is a characteristic feature of ER stress and UPR activation, and was observed in the striatum and hippocampus after transient bilateral occlusion of common carotid arteries (Tajiri et al., 2004), as well as in other models of ischemia and reperfusion (Paschen et al., 1998, 2003; Roberts et al., 2007; Nakka et al., 2010; Osada et al., 2010). Hippocampal neurons from $\mathrm{CHOP}^{-1-}$ mice exhibited a significantly lower rate of cell death, when compared with wildtype animals, indicating that transient ischemia-induced cell death is mediated by CHOP induction (Tajiri et al., 2004).

Caspase-12 is an ER protease typically activated under ER stress conditions, and early studies showed a role for this caspase in ERstress induced cell death (e.g. Nakagawa et al., 2000). Caspase-12 activation was detected in the ischemic brain at $5 \mathrm{~h}$ of reperfusion after occlusion of the middle cerebral artery (MCAO), which was accompanied by an increase in caspase- 12 protein levels (Shibata et al., 2003; Nakka et al., 2010). An upregulation of caspase-12 mRNA and protein was also found in the striatum and cerebral cortex after permanent MCAO in rats (Mouw et al., 2003). However, the role of this protease in neuronal demise in the ischemic brain remains to be determined. In fact, it was proposed that caspase-12 acts mainly as a dominant negative in the regulation of caspase- 1 activity and the main role of the proteolytic activity of caspase-12 may be in the processing of the protease (Roy et al., 2008).

A distinct mechanism involved in the alteration of transcription activity during the UPR is mediated by activation of the endonuclease IRE1, which processes the mRNA for XBP1 (X-box binding protein 1) (Yoshida et al., 1998; Calfon et al., 2002). These mRNAs are translated in a processed XBP1 protein (XBP1 ${ }^{\text {proc }}$ ) which is translocated to the nucleus, serving as a transcription factor that induces the expression of ER genes, such as grp78 and grp94 (Calfon et al., 2002). Although the xbp1 mRNA was found to be processed early after reperfusion following global and focal ischemia, a delayed increase in XBP1 ${ }^{\text {proc }}$ was only observed in the former conditions (Paschen et al., 2003). The blockade of translation after transient cerebral ischemia may prevent de novo synthesis of XBP1 ${ }^{\text {proc }}$ and the downstream effects on gene expression.

The unfolded proteins accumulated in the ER bind glucoseregulated protein 78 (GRP78), an important sensor of the UPR, leading to the dissociation of binding partners that act as transcription factors. These proteins translocate to the nucleus, where they induce the expression of genes coding for molecular chaperones and folding enzymes, including GRP78 itself, HERP (homocysteine-inducible, ER-stress inducible protein), GRP94, calnexin and PDI (protein disulphide isomerase) (Kokame et al., 2000; Kokame et al., 2001). An increase in the expression of the grp94, grp78, herp, calnexin and pdi genes was observed after transient ischemia using different models (Aoki et al., 2001; Paschen et al., 2003; Truettner et al., 2009; Urban et al., 2009), and this effect was correlated with a small upregulation of GRP78 and GRP94 protein levels in the hippocampus of rats subjected to the two-vessel occlusion brain ischemia model (Truettner et al., 2009). A significant upregulation of GRP78 protein levels was also observed in the ischemic territory after transient MCAO in mice (Shibata et al., 2003). 
Taken together, the studies described above clearly point to the induction of ER stress indicators in brain ischemia. However, additional studies are required to determine their relative role in neuronal death.

\subsection{Autophagy in brain ischemia}

Macroautophagy (autophagy from hereafter) represents the degradation of any kind of intracellular components in the lysosomes, and starts with the formation of a double membrane vesicle (autophagosome) that sequester portions of the cytoplasm that, when fused with the lysosome (autolysosome), allows the degradation of cargo content by lysosomal proteases (Yang and Klionsky, 2009). This quality control mechanism is highly active under physiological conditions being responsible for the regulation of mitochondrial turnover and clearance of protein aggregates (Choi et al., 2013). Mice lacking the essential autophagic genes Atg5 and Atg7 in the central nervous system showed reduced lifespan, massive neuronal death, formation of inclusion bodies and accumulation of ubiquitinated proteins (Hara et al., 2006; Komatsu et al., 2006). However, little is known about how this pathway is altered after brain ischemia.

An increase in autophagosomes, autolysosomes and LC3-II protein levels was observed in CA1 neurons after 20 min of 2vessel occlusion in rats followed by $4-24 \mathrm{~h}$ of reperfusion, suggesting activation of autophagy (Liu et al., 2010). However, when lysosome inhibitors were applied, LC3-II protein levels failed to elevate indicating an autophagic-flux impairment in the hippocampus (Liu et al., 2010). An upregulation in LC3-II protein levels was also observed during reperfusion after $1 \mathrm{~h}$ of transient MCAO, but in this case no changes in the autophagic-flux were observed in the penumbra region (Zhang et al., 2013a). This discrepancy may be due to the differences in the methodology used to induce brain ischemia (global $v s$ focal ischemia) and or to intrinsic properties of the brain region analysed, which was different in the two sets of experiments. The class III phosphoinositide 3-kinase (PI3K) inhibitor 3-methyladenine (3-MA), a wellknown inhibitor of autophagosome expansion thus inhibiting autophagy, further increased the infarct volume after transient MCAO and reinforced apoptotic cell death $24 \mathrm{~h}$ after OGD in cultured cerebrocortical neurons (Zhang et al., 2013a). This increase in vulnerability to OGD in the presence of 3-MA was due to the defective mitochondrial clearance by the autophagic pathway thus failing in aborting apoptosis (Adhami et al., 2007; Zhang et al., 2013a). At this point it is still not understood how lysosomes are involved in inducing apoptosis under ischemic conditions. One possible mechanism is through a Bax-dependent lysosomal-membrane permeabilization with the consequent cathepsin B and D translocation to the cytosol, thereby triggering apoptosis (Erdal et al., 2005).

Autophagy was also shown to play a role in ischemic tolerance. Pheochromocytoma PC12 cells subjected to $6 \mathrm{~h}$ of ischemic preconditioning showed a decreased survival when further exposed to lethal-OGD for $15 \mathrm{~h}$ in the presence of 3-MA (Park et al., 2009). Ischemic preconditioning (30 $\mathrm{min}), 24 \mathrm{~h}$ prior to a lethal exposure to OGD in the presence of 3-MA abolished the upregulation of HSP70, HSP60 and GRP78 (protective markers), and upregulated CHOP, cleaved caspase-12 and caspase-3 (Sheng et al., 2012). These alterations suggest that autophagic induction during ischemic preconditioning reduces the excessive ER stress caused by harmful ischemia (Sheng et al., 2012).

\section{UPS}

The ubiquitin-proteasome system (UPS) is the major intracellular machinery for protein degradation (Ciechanover, 1994). UPS protein targets are first polyubiquitinated before being degraded by the proteasome. Under basal conditions, UPS components are found in all subcellular components including the nucleus, plasma membrane and mitochondria, and are responsible for maintaining cellular homeostasis by regulating several important processes such as cell division, cell death, signal transduction and transmembrane transport (Wagner et al., 2011).

\subsection{Ubiquitin}

Ubiquitin is a small, heat-stable and highly conserved 76-amino acid protein with $8.5 \mathrm{kDa}$, which can be covalently attached to other proteins (Hershko and Ciechanover, 1998; Fang and Weissman, 2004). Ubiquitin was first described as a thymic hormone and to have lymphocyte-differentiation properties (Goldstein, 1974; Goldstein et al., 1975; Schlesinger et al., 1975; Hershko and Ciechanover, 1998), before its role in selective degradation of proteins was uncovered. Additional studies were required to identify a small protein, named APF-1 (ATP-dependent proteolysis factor 1), which was shown to play an important role in the selective degradation of APF-1 modified proteins (Ciechanover et al., 1978, 1980). Later on, given the similarities on the amino acid sequence and physical properties, it was found that APAF-1 was indeed ubiquitin (Wilkinson et al., 1980).

Substrate proteins can be modified either by a monoubiquitin, multiple monoubiquitin (multi-ubiquitination) or by a polyubiquitin chain (polyubiquitination). For the latter process, any of the seven lysine residues (Lys6, Lys11, Lys27, Lys29, Lys33, Lys48, Lys63) of ubiquitin can be linked to the previous one, resulting in a sizeable increase of the chains with different configurations (Grabbe et al., 2011). In an early attempt to quantify the relative abundance of polyubiquitin chains, using an yeast model, it was found that K48 polyubiquitin chains are the most abundant ones (29\%), followed by K11 (28\%), K63 (16\%), K6 (10.9\%), K27 (9\%), K33 (3.5\%) and K29 (3.2\%) (Xu et al., 2009b). However, the amount of proteins that are single ubiquitinated was not assessed in this case. A different study also performed in yeast showed that $56 \%$ of all ubiquitin modified proteins are either monoubiquitinated or have an end-cap ubiquitin, and the remaining bulk is given to polyubiquitin modified proteins (Ziv et al., 2011). In this case the relative abundance of different types of polyubiquitin chains was quite different from the early observations in yeast: the K48 polyubiquitin chains were once again the most prevalent ones (21\%), followed by K63 (18\%), K29 (5\%), K11 (0.6\%), K33 ( 0.1\%) and K27 ( 0.1\%), while K6 was not detected (Ziv et al., 2011). These differences may result from the different experimental approaches used in both works.

The myriad of polyubiquitin modifying possibilities is responsible for the high complexity of this system, thus regulating different outcomes in the modified protein. While K48 polyubiquitin chains target proteins for proteasomal degradation in a process that requires at least four ubiquitin molecules (Fang and Weissman, 2004; Ye and Rape, 2009; Lander et al., 2012), noncanonical K63 polyubiquitin chains are associated with nonproteolytic functions (Nathan et al., 2013) such as DNA repair, kinase activity modulation (Pickart, 2004; Chernorudskiy and Gainullin, 2013), regulation of plasma membrane protein internalization through the endocytic pathway, and delivery of internalized proteins for lysosomal degradation (Grabbe et al., 2011; Wagner et al., 2011). The ubiquitination process is also important as a protein quality control mechanism. Initial studies have shown that almost $30 \%$ of the newly synthesized proteins arise as defective ribosomal products, being part of them ubiquitinated (Schubert et al., 2000). However, the extent of ubiquitination in the defective ribosomal products and whether these proteins are ubiquitinated after or during the translation 
process were not investigated. More recently, two independent studies further addressed this issue using yeast as a model, but although similar approaches were used, distinct results were obtained. One report showed ubiquitination in $12-15 \%$ of newly synthetized proteins while translation is occurring, being the effect enhanced by misfolding agents and HSP70 inhibitors (Wang et al., 2013). The same authors showed that protein ubiquitination induced by misfolding agents is prevented by ubiquitin mutants lacking lysine 48 (Wang et al., 2013). In contrast, the other study reported that cotranslational ubiquitination occurs at a rate of 1$5 \%$ under basal conditions by a mechanism dependent on the activity of the Hul5, Hrd1 and Doa10 E3 ligases (Duttler et al., 2013).

The importance of Lys11-linked polyubiquitin chains in regulating cell cycle has been recently updated (Wickliffe et al., 2011), and along with Lys6, Lys27 and Lys29, Lys33-linked polyubiquitin chains can also direct proteins for proteasomal degradation (Xu et al., 2009b; Kim et al., 2011; Kulathu and Komander, 2012). In addition, several studies have shown the crosstalk between ubiquitination and other post-translational modifications, including phosphorylation and acetylation, thereby increasing the complexity of this signaling network (Beltrao et al., 2012). Surprisingly, in some cases, mono- and multi-monoubiquitination can also act as proteasomal degradative signals (Guterman and Glickman, 2004; Boutet et al., 2007; Dimova et al., 2012; Shabek et al., 2012).

\subsection{Ubiquitination machinery}

As a post-translational modification, the ubiquitination process, i.e., the process of adding ubiquitin to a substrate protein, and the removal of these ubiquitin molecules at a later point, is a finely tuned process governed by a cascade of ubiquitination enzymes and by deubiquitinating enzymes (DUBs), respectively. Almost 3\% of the human genome is devoted to the ubiquitination machinery highlighting the importance of this process in cell survival and homeostasis.

Protein ubiquitination occurs through a sequential action of three or four different classes of enzymes, E1 or ubiquitin activating enzyme, E2 or ubiquitin conjugating enzyme and E3 or ubiquitin ligase (Fig. 2). The human genome encodes for $2 \mathrm{E} 1 \mathrm{~s}$, $\sim 40$ E2s and $~ 650$ E3s (Ye and Rape, 2009; de Bie and Ciechanover, 2011). E1 is the first enzyme involved in the ubiquitination cascade. It binds to $\mathrm{Mg}^{2+}$-ATP and subsequently to ubiquitin in order to activate its C-terminal Gly residue (Jin et al., 2007; Finley et al., 2012). ATP hydrolysis generates an ubiquitin adenylate, followed by ubiquitin transference to a Cys residue of E1 through a thiol-ester linkage, with the release of adenosine monophosphate (AMP) (Hershko et al., 1983; Jin et al., 2007). Since this activating step is sequentially repeated, each fully loaded E1 carries two molecules of ubiquitin, one as a thiol-ester and the other as an adenylate (Fang and Weissman, 2004; Finley et al., 2012). Activated ubiquitin is then transferred to a conserved core domain of $\sim 150$ residues (ubiquitin-conjugating (UBC) domain) of an E2 conjugating enzyme that includes an invariant cysteine residue responsible for accepting ubiquitin from E1 (Fang and Weissman, 2004; Ye and Rape, 2009). In the third step, ubiquitin is transferred, specifically, to a substrate protein by an E3 ligase. Two different classes of E3 ligases are responsible for the interaction with the E2 conjugating enzymes and can serve either as catalytic intermediates, or mediate the direct transfer of ubiquitin to the substrate. Homologous to E6-AP Carboxyl Terminus (HECT) E3 ligases serve as intermediate ubiquitin acceptors through the formation of a thiol-ester linkage between ubiquitin and the Cys residue in the HECT domain before ubiquitin is attached to the substrate (Fang and Weissman, 2004; de Bie and Ciechanover, 2011). On the other hand, Really Interesting New Gene (RING) E3 ligases act only as "scaffold" proteins forming an E2-substrate protein complex that allows the direct transfer of ubiquitin to the target protein (Fang and Weissman, 2004; Deshaies and Joazeiro, 2009; de Bie and Ciechanover, 2011). Despite the differences in the mechanisms of ubiquitin transference to the substrate proteins, both types of E3 ligases lead to the formation of an isopeptide bond between the $\mathrm{C}$ terminal Gly of ubiquitin and a $\varepsilon-\mathrm{NH}_{2}$ group of an internal Lys of the substrate. However, ubiquitin can also be added to other residues (recently reviewed in de Bie and Ciechanover, 2011). While the interaction between the E2 and E3 determines the type of polyubiquitin linkage, an additional subset of enzymes, E4, or ubiquitin elongating enzymes, allows the elongation of ubiquitin chains on those proteins that have been modified by activated ubiquitin (Koegl et al., 1999; Hoppe, 2005; Finley et al., 2012).

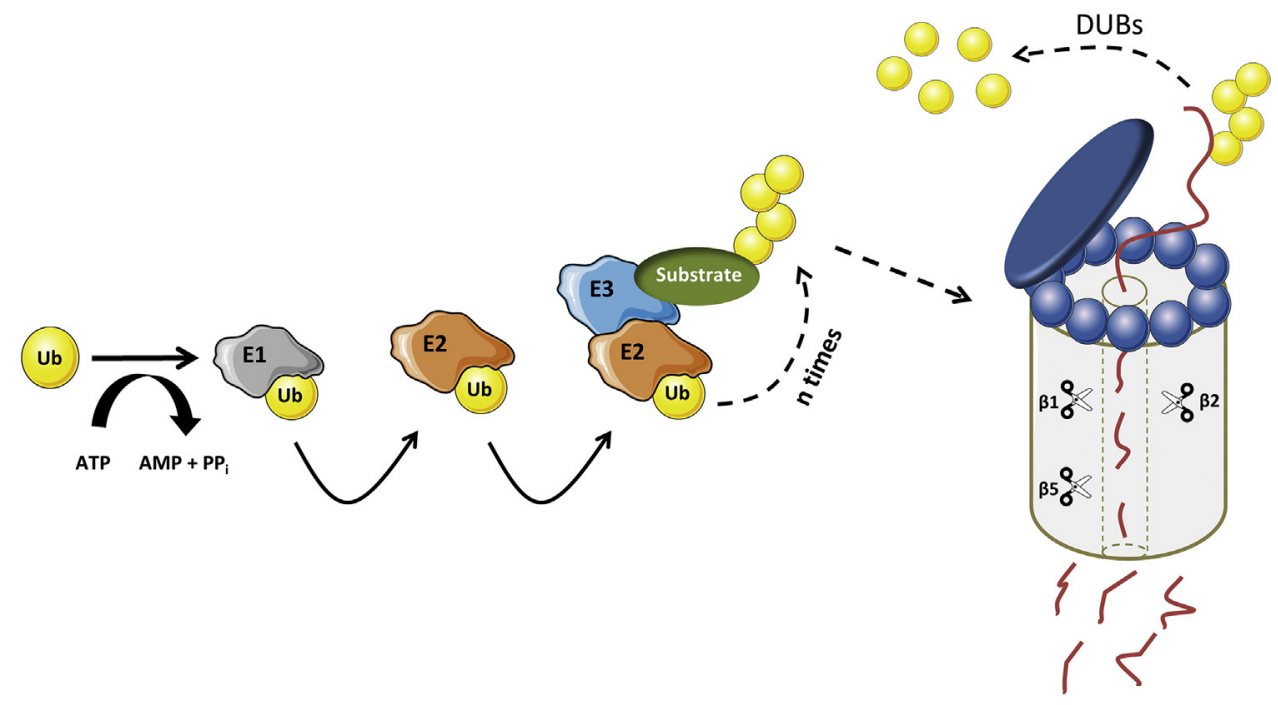

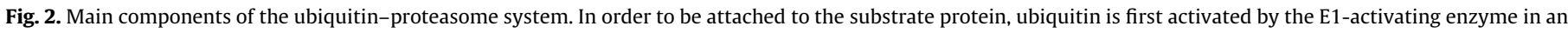

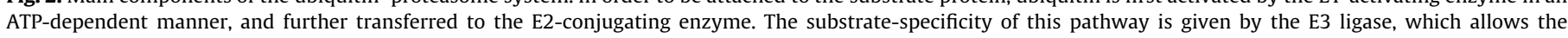

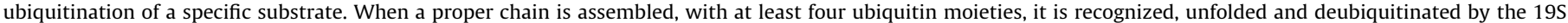

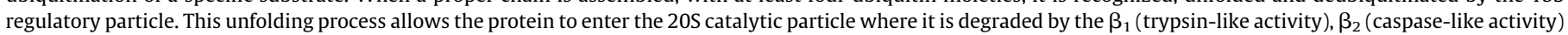
and $\beta_{5}$ (chymotrypsin-like activity) subunits. At the end, small peptides are generated and ubiquitin is regenerated. 


\subsection{Deubiquitinating enzymes}

The ubiquitination process can be counteracted by deubiquitinating enzymes (DUBs). Five major classes of DUBs have been described: ubiquitin C-terminal hydrolases (UCHs), ubiquitinspecific proteases (USPs), Machado-Joseph disease protein domain proteases, ovarian tumor proteases and JAMM motif proteases (Love et al., 2007). Almost all DUBs are cysteine proteases, except the JAMM family which are metalloproteases (Todi and Paulson, 2011). DUBs may be intrinsic to the 26S proteasome (e.g. Rpn11), or may associate reversibly with the proteasome (e.g. Uch37 and Usp14) (Koulich et al., 2008; Tai et al., 2010; Liu and Jacobson, 2013), but most of them have a cytosolic localization. The overall function of DUBs is to cleave ubiquitinlinked molecules after the C-terminus of the last residue of ubiquitin (Gly76), being essential to: (i) the maintenance of monomeric ubiquitin pool, either by cleaving the ubiquitin precursor or by trimming polyubiquitin chains; (ii) rescue proteins targeted for degradation, allowing the cell to adapt quickly to physiological changes, and (iii) prevent ubiquitinproteasome dependent protein degradation (Guterman and Glickman, 2004; Komander et al., 2009). Activation of the DUBs Usp14 and Uch37, either by polyubiquitin chains or their chemical mimetics, stimulates the 19S associated ATPases thereby opening the 20S closed gate, and thus promoting peptide hydrolysis (Peth et al., 2009, 2013).

\subsection{Proteasome}

The 26S proteasome is a $2.5 \mathrm{MDa}$ multisubunit complex responsible for controlled ATP-dependent degradation of polyubiquitinated proteins (Xie, 2010). It is composed of a catalytic 20S core particle (CP or $20 \mathrm{~S}$ proteasome) associated with one $\left(\mathrm{RP}_{1} \mathrm{CP}\right)$ or two $\left(\mathrm{RP}_{2} \mathrm{CP}\right) 19 \mathrm{~S}$ regulatory particles (RP or $19 \mathrm{~S}$ proteasome), that are responsible for detecting, deubiquitinating and unfolding ubiquitinated proteins (da Fonseca et al., 2012; Djakovic et al., 2012). Although $\mathrm{RP}_{1} \mathrm{CP}$ and $\mathrm{RP}_{2} \mathrm{CP}$ can be observed in several cell types, including neuronal, kidney and liver cells, the proportion of $\mathrm{RP}_{1} \mathrm{CP}$ and $\mathrm{RP}_{2} \mathrm{CP}$ to free $20 \mathrm{~S}$ proteasome is often higher in neurons (Tai et al., 2010). The highest amount of $\mathrm{RP}_{1} \mathrm{CP}$ is thought to be better suited for performing a vectorial process which involves substrate capture and release (Baumeister et al., 1998). The 26S proteasome consists of at least 66 resident subunits and associated proteins, e.g. E3 ligases and assembling factors, such as molecular chaperones and others (Leggett et al., 2002; Tai et al., 2010; Xie, 2010).

Once a protein is committed for proteasomal degradation, by linking at least four ubiquitin moieties and a proper polyubiquitin chain (Glickman and Ciechanover, 2002; Lander et al., 2012), the interaction with the $26 \mathrm{~S}$ proteasome and subsequent deubiquitination allows the translocation to the proteasome followed by degradation (Fig. 2). At the end, small peptides ranging from 2 to 20 amino acids and free ubiquitin are regenerated (Glickman and Ciechanover, 2002). The catalytic activity of the $26 \mathrm{~S}$ proteasome is significantly enhanced in the presence of ubiquitinated substrates whereas the 20S activity remains unchanged (Peth et al., 2009). This supports a role for the $26 \mathrm{~S}$ proteasome in the selective degradation of ubiquitinated substrates.

The 20S proteasome is a $\sim 670 \mathrm{kDa}$ barrel-shaped structure composed of 28 subunits arranged in a four stacked ring structure: two $\alpha_{1-7}$ outer rings and two $\beta_{1-7}$ inner rings (da Fonseca and Morris, 2008). In the center of the ring, there is a narrow pore where a protein targeted for degradation can enter in an unfolded state. In the free CP this pore is closed by the $\mathrm{N}$ terminus of the $\alpha$-subunits, namely $\alpha_{2}, \alpha_{3}$ and $\alpha_{4}$ (Xie, 2010). However, the truncation of the $\alpha 3 \mathrm{~N}$-terminal is enough to keep the pore open and increases the degradation of small peptides (Peth et al., 2009). Besides closing the pore, $\alpha$-subunits are also responsible for compartmentalizing the catalytic $\beta$-subunits, thereby preventing uncontrolled cleavage of cytosolic proteins. Moreover, a proteomic approach revealed that the $\alpha_{7}$ subunit interacts with proteins involved in the processing and splicing of RNA (Fedorova et al., 2011). The $\beta$ ring also forms a central chamber where the peptidylglutamyl-like (cleaving after acidic residues), trypsin-like (cleaving after basic residues) and chymotrypsin-like (cleaving after hydrophobic residues) activities of the $20 \mathrm{~S}$ proteasome are mediated by the $\beta_{1}, \beta_{2}$ and $\beta_{5}$ subunits, respectively (Fig. 2) (Groll et al., 1997; Beck et al., 2012).

The other component of the $26 \mathrm{~S}$ proteasome, the $19 \mathrm{~S}$ regulatory particle (RP), is a $\sim 700 \mathrm{kDa}$ multisubunit complex composed of at least 18 subunits. The $19 \mathrm{~S}$ proteasome serves to recognize, deubiquitinate and unfold the substrate proteins in order to make them suitable to enter into the $20 \mathrm{~S}$ catalytic pore. It is divided in two biochemically distinct sub-complexes: the lid and the base (Hershko and Ciechanover, 1998; Sakata et al., 2012; Tomko and Hochstrasser, 2013). The lid consists of eight non-ATPase subunits, Rpn3, Rpn5-9, Rpn12 and Rpn11 (a DUB enzyme). The base contains six distinct AAA+ ATPases, Rpt1-6, and four non-ATPase subunits, Rpn1, Rpn2, Rpn10 and Rpn13 (Lander et al., 2012; Tomko and Hochstrasser, 2013). The interaction of polyubiquitinated proteins with the RP base occurs on two intrinsic proteins, Rpn10 and Rpn13, which are apically located in order to better capture ubiquitinated substrates (Sakata et al., 2012). Rpn10 binds ubiquitin conjugates through its C-terminus Ubiquitin-Interacting Motif (UIM), and a similar function is mediated by the Rpn13 subunit through a conserved amino-terminal region named pleckstrin-like receptor for ubiquitin (Pru) domain (Husnjak et al., 2008; Schreiner et al., 2008; Sakata et al., 2012). The Pru domain is also important to attach Rpn13 to the proteasome (Schreiner et al., 2008).

Although recognition of ubiquitinated proteins is, to a certain extent, considered to be a stochastic process, several proteins such as Rad23 and Dsk2 have been shown to act as shuttling factors and direct ubiquitinated proteins to the 26S proteasome (Guerrero et al., 2006). These proteins interact with large scaffold proteins of the base, namely Rpn1 and Rpn2 (Husnjak et al., 2008). Another shuttling factor, the p62/sequestosome1, associates with the $26 \mathrm{~S}$ proteasome through the N-terminal domain (Seibenhener et al., 2004; Myeku and Figueiredo-Pereira, 2011), and participate in the selective recognition and degradation of ubiquitinated cargo by selective autophagy (Lamark et al., 2009). While Rpn1 is responsible for binding shuttling factors such as $\operatorname{Rad} 23$ and Dsk2 (Elsasser et al., 2002, 2004; Rosenzweig et al., 2012), and the non-obligatory deubiquitinating enzyme Ubp6/Usp14 (Leggett et al., 2002; Elsasser et al., 2004; Rosenzweig et al., 2012), Rpn2 only binds the Rpn13 subunit (Schreiner et al., 2008; Rosenzweig et al., 2012). This specific binding and the delivery of ubiquitinated proteins to the proteasome by shuttling factors is driven by the $\mathrm{N}$ terminal ubiquitin-like domain (UBL), while the C-terminal ubiquitin associated domain (UBA) is responsible for ubiquitin binding (Rosenzweig et al., 2012).

The ATPase ring of the 19S proteasome is arranged in a spiral case and constitutes the driving force to unfold and pull the target proteins to be degraded inside the catalytic core (Lander et al., 2012). The Rpt2 subunit appears to be the only one required for $C P$ opening and substrate entry (Kohler et al., 2001). Two independent studies attributed another function to the base ATPases, in preventing protein aggregation, by acting as chaperones, and in mediating protein refolding and not unfolding (Braun et al., 1999), and the Rpt5 subunit may also bind polyubiquitin chains as shown by crosslinking studies (Lam et al., 2002). 


\subsection{Immunoproteasome}

In response to viral, bacterial or other types of stress, the constitutive catalytic subunits $\beta_{1}, \beta_{2}$, and $\beta_{5}$ can be replaced by three inducible subunits, low molecular weight protein 2 (LMP2 or $\beta 1 \mathrm{i})$, multicatalytic endopeptidase complex like 1 (MECL1 or $\beta 2 \mathrm{i}$ ), and $\beta 5$ i (LMP7), respectively (Loukissa et al., 2000). The proteasomes containing these subunits are usually referred to as immunoproteasome (i-proteasome). However, a mixture of the standard and i-proteasome catalytic subunits may be found at the $20 S$ catalytic core (Dahlmann et al., 2000), and was shown to contribute to differences in catalytic core enzymatic characteristics and cleavage of model substrates (Dahlmann et al., 2000). The iproteasomes play an important role in the immune system, generating immunogenic peptides for antigen presentation on MHC class I and recognition by cytotoxic T lymphocytes (Rock et al., 1994; Goldberg et al., 2002). Although in young healthy human brain i-proteasomes are almost absent, they have been detected in brain areas from elderly subjects as well as from patients affected by Alzheimer (Mishto et al., 2006) and Huntington diseases (Diaz-Hernandez et al., 2003), and in Multiple Sclerosis (Mishto et al., 2010). Transient focal cerebral ischemia was also shown to upregulate the protein levels of i-proteasome subunits LMP2 and LMP7 in the parietal cortex and hippocampus (Lu and Wang, 2012). This upregulation of i-proteasomal subunits may contribute to recover the proteasomal activity following a transient cerebral ischemic stroke, leading to efficient clearance of unwanted proteins and thus possibly providing neurons an increased tolerance to transient ischemia.

\section{Role of UPS in nervous system}

In yeast cells, the majority of proteasomes have been detected in the cell nucleus (Russell et al., 1999). However, in mammalian cells, proteasomes are mainly located at the cytoplasm, with a very high concentration close to centrosome (Wigley et al., 1999). By contrast, i-proteasomes are specifically positioned at the endoplasmic reticulum (Brooks et al., 2000). A nuclear localization signal may also direct proteasomes to the cell nucleus (Tanaka et al., 1990; Reits et al., 1997), namely after induction of cell stress (Ogiso et al., 2002), where they accumulate in focal subdomains (von Mikecz, 2006). Human plasma also contains 20S proteasomes, which were probably released from dying cells, and can potentially be used as diagnostic markers (Wada et al., 1993; LavabreBertrand et al., 2001; Egerer et al., 2002).

Neurons are a very specialized post-mitotic cell type, and several components of the UPS are present in both pre- and postsynaptic compartments. In the nervous system, the UPS regulates several aspects of synaptic function, such as spinogenesis (Hamilton et al., 2012), presynaptic neurotransmission (Willeumier et al., 2006; Jiang et al., 2010), long-term potentiation (Dong et al., 2008; Cajigas et al., 2010; Pavlopoulos et al., 2011), synaptic scaling (Hou et al., 2011), apical dendrite outgrowth/ polarization (Hamilton and Zito, 2013; Miao et al., 2013; Vadhvani et al., 2013), dendritic arborization (Puram et al., 2013), axon growth (Yang et al., 2013), and synapse formation and elimination (Yi and Ehlers, 2007).

Rat cerebrocortical cell extracts possess a higher proportion of 26 S proteasomes ( $\sim 57 \%$ ), when compared to HeLa cells ( $\sim 39 \%$ ) and to rat liver/kidney cell extracts ( $51 \%)$ (Tai et al., 2010). This difference may suggest that selective protein degradation is a more prominent and controlled process in the brain when compared to other organs. In the rodent brain tissue, the mean levels of unconjugated ubiquitin $(122.6 \mathrm{pmol} / \mathrm{mg}$ ) are comparable to the conjugated form $(111.6 \mathrm{pmol} / \mathrm{mg})$, and the proportion of polyubiquitin chains are to a certain extent similar to those observed in yeast cell extracts $(\mathrm{K} 48>\mathrm{K} 63>\mathrm{K} 11>\mathrm{K} 6>\mathrm{K} 33>\mathrm{K} 27>\mathrm{K} 29)$ (Na et al., 2012). This points towards the importance of the UPS in the nervous system, and suggests that selective protein degradation is a highly controlled process.

Synaptic activity can alter significantly the neuronal proteome within minutes after postsynaptic receptor activation. In fact, several components of the UPS can also be regulated upon NMDAR activation (Colledge et al., 2003; Ehlers, 2003). Studies performed in cultured hippocampal neurons showed that increasing synaptic activity enhances proteasome activity and induces a redistribution of the $26 \mathrm{~S}$ proteasome from dendritic shafts to dendritic spines, as shown using the degradation reporter $\mathrm{Ub}^{\mathrm{G} 76 \mathrm{~V}}$-GFP and the proteasome reporter Rpt1-GFP, respectively (Dantuma et al., 2000; Bingol and Schuman, 2006). These effects were promoted by Rpt 6 phosphorylation on the serine 120 residue by CaMKII $\alpha$ (Djakovic et al., 2009; Djakovic et al., 2012), and prevented by CaMKII inhibition (Djakovic et al., 2009) or by knocking down CaMKII $\alpha$ with iRNA (Bingol et al., 2010). Similarly, activation of NMDAR also stimulates the Ubiquitin C-terminal Hydrolase L1 (UCH-L1), thereby increasing free monomeric ubiquitin levels (Cartier et al., 2009). This contrasts with the results obtained using light-controlled excitation of individual presynaptic terminals of hippocampal neurons, which increased polyubiquitin conjugation but was without effect on the redistribution of free ubiquitin and proteasomes (Hou et al., 2011). Furthermore, upregulation of excitatory activity by incubation of hippocampal neurons with bicuculline for $48 \mathrm{~h}$ was shown to increase ubiquitin conjugation in postsynaptic density fractions (Ehlers, 2003).

Postsynaptically, the UPS is responsible for regulating the levels and/or localization of several proteins. For example, the NMDAR subunits, GluN1 and GluN2B, are regulated in an activitydependent manner by the Fbx2 and Mind Bomb-2 (Mib2) E3 ligases, respectively (Kato et al., 2005; Jurd et al., 2008) (Fig. 3). The postsynaptic scaffold proteins PSD-95, Shank and GKAP undergo selective activity-dependent ubiquitination (Ehlers, 2003), and while the Murine-double minute $2(\mathrm{Mdm} 2)$ is the putative E3 ligase for PSD-95 (Ehlers, 2003; Tsai et al., 2012), knockdown of endogenous TRIM3 E3 ligase increases the protein levels of guanylate kinase-associated protein (GKAP) and Shank (Hung et al., 2010), suggesting that these two proteins may share a common E3 ligase (Fig. 3). GKAP phosphorylation by CaMKII $\alpha$ on Ser54 promotes its removal from synaptic sites, polyubiquitination and subsequent degradation by the proteasome (Shin et al., 2012). All these synaptic proteins and others (e.g. bassoon, vesicular glutamate transporter 1 and 2, vesicle-associated membrane protein, synapsin) were shown recently to be modified by ubiquitin, in a proteomic study using an antibody that recognizes a specific signature (K-GG peptides) generated after trypsinization of ubiquitin-modified proteins (Na et al., 2012).

The UPS also mediates the internalization of several membraneassociated synaptic proteins. The initial studies showed that AMPA-induced internalization of AMPAR was abolished by the proteasome inhibitor MG132, but no ubiquitination of AMPAR subunits was observed at that time (Patrick et al., 2003). Additional studies suggested that this internalization is due to a reduced stabilization of AMPA receptors into synaptic sites as a result of PSD-95 degradation (Colledge et al., 2003). More recently, Nedd4 (neuronal-precursor cell-expressed developmentally downregulated gene 4) was identified as the putative E3 ligase for GluA1 (Schwarz et al., 2010), and knockdown of Nedd4 prevented GluA1 C-terminal K868 residue ubiquitination, abolishing AMPAR internalization (Lin et al., 2011) (Fig. 3). The AMPAR GluA2 subunit is also ubiquitinated in response to bicuculline treatment (Lussier et al., 2011). Yet, the E3 ligase responsible to ubiquitinate GluA2 subunit differs from the one responsible for GluA1 ubiquitination. The available evidences suggest that the RNF167 E3 ligase is 


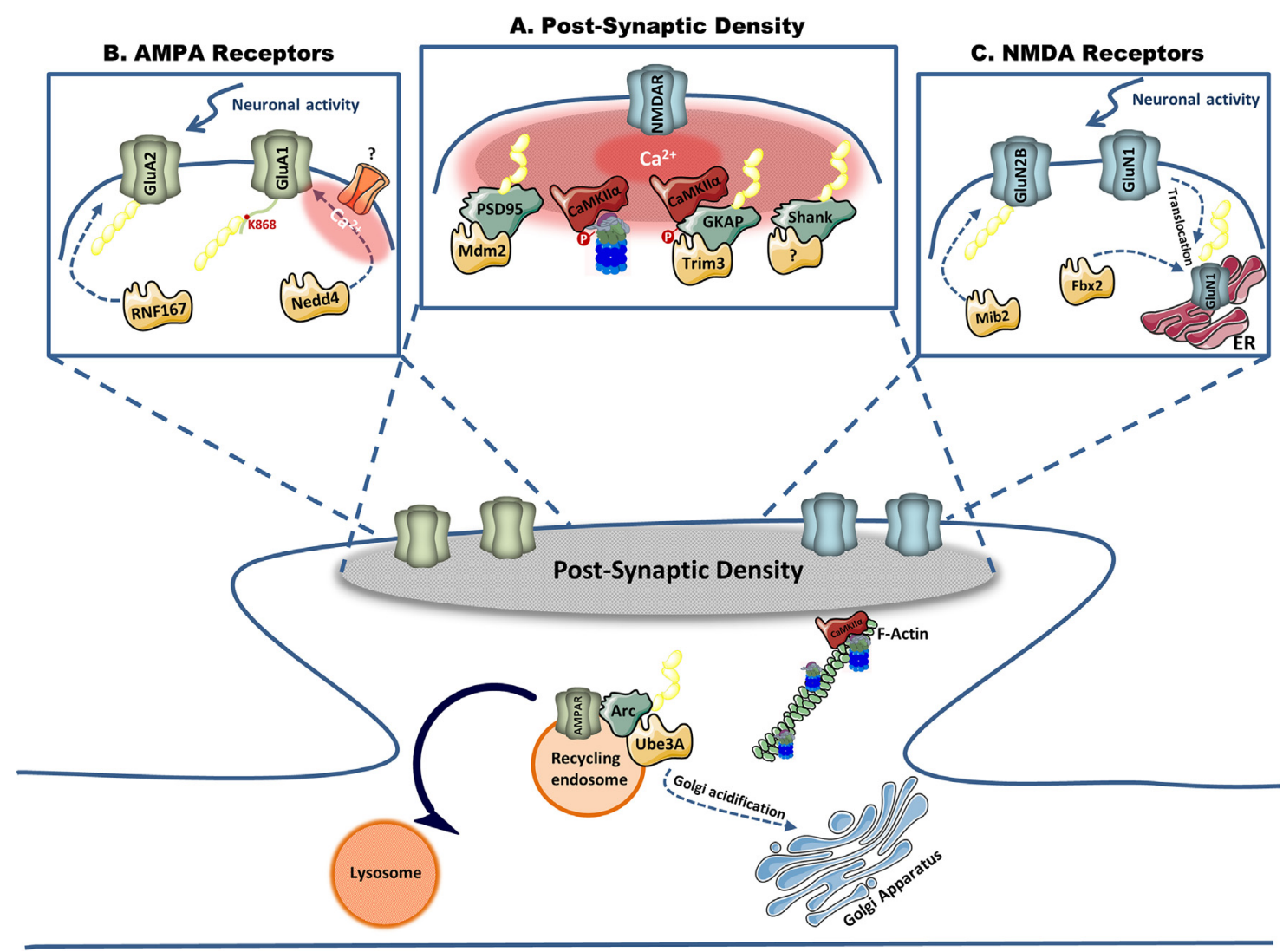

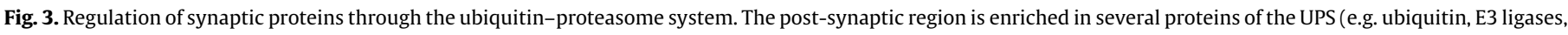

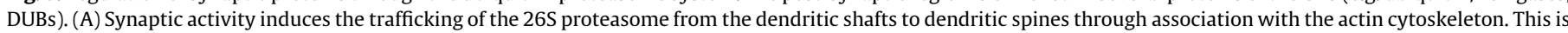

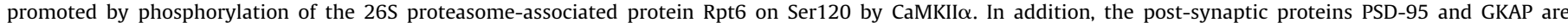

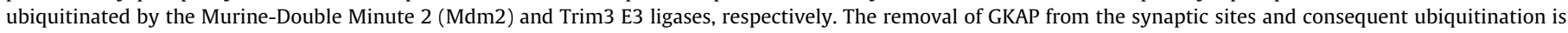

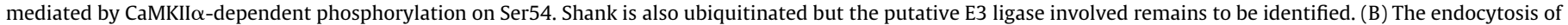

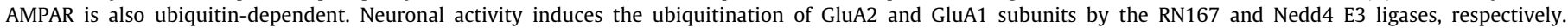

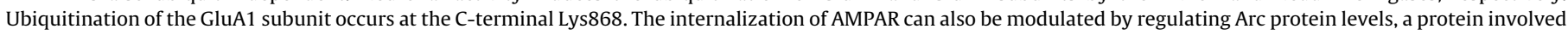

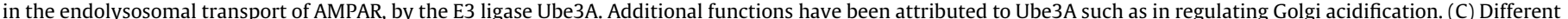

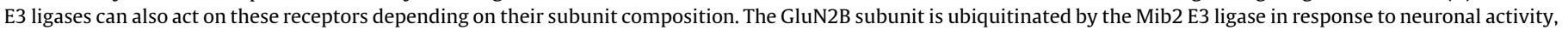
whereas the obligatory GluN1 subunit is ubiquitinated by the Fbx2 E3 ligase. This occurs when the subunit is internalized and at the endoplasmic reticulum level.

involved in GluA2 ubiquitination and, accordingly, knockdown of this ligase was shown to increase AMPAR mediated currents by increasing the surface expression of GluA2 and to reduce GluA2 ubiquitination following bicuculline treatment (Lussier et al., 2012) (Fig. 3). There is still some controversy regarding the mechanism of AMPAR internalization promoted by synaptic activity, and in particular the role of ubiquitin-mediated degradation. While some studies showed that internalization and degradation is blocked by proteasome inhibitors (Hou et al., 2011; Lin et al., 2011), others revealed a dendritic co-localization of the internalized receptors with the lysosomal marker Lamp1A, suggesting that internalized receptors are delivered to the lysosomes (Schwarz et al., 2010). Since the internalization of plasma membrane proteins through the endocytic pathway can be mediated by non-canonical polyubiquitin chains (Groothuis et al., 2006), the decreased degradation in the presence of proteasome inhibitors can still be attributed to the lysosomes since under these conditions there is a decrease in free ubiquitin levels thus interfering with the ubiquitin-mediated internalization process (Dantuma et al., 2006).

Dysfunction of the ubiquitination and deubiquitination machineries, mutations in ubiquitin, proteasomal impairment, and mutations in proteasome substrates affecting their rate of degradation underlie the pathogenesis of many neurodegenerative diseases (Dennissen et al., 2012). For instance, the ataxic mouse $\left(a x^{J}\right)$, which results from a mutation in the ataxia gene encoding for the DUB Usp14, shows deficits in presynaptic neurotransmitter release and short-term plasticity (Wilson et al., 2002), in addition to a $35 \%$ decrease in free ubiquitin levels when compared to wildtype mice (Walters et al., 2008). Usp14 overexpression rescued the levels of free ubiquitin in the brain, as well as the lifespan and motor activity of $\mathrm{ax}^{\mathrm{J}}$ mice to values similar to the wildtype (Crimmins et al., 2006). Notably, all the negative effects observed in the $a x^{J}$ phenotype were attributed to the decreased free ubiquitin levels, resulting ultimately in synaptic dysfunction. Restoring free ubiquitin levels prevented the early death at 8 weeks of age, body weight loss and presynaptic dysfunction observed in the ataxic mice (Chen et al., 2011). The deficit in neurotransmitter release in the $\mathrm{ax}^{\mathrm{J}}$ mice is in accordance with the results showing that inhibition of Uch-L1, another DUB abundantly expressed in neurons, also decreases free ubiquitin levels, thus increasing the number of synaptic vesicles (Cartier et al., 2009). Mutations in the RING finger E3 ligase Listerin, observed in the lister mouse model, also induce biochemical, cellular and neurological alterations similar to those observed in many neurodegenerative processes, including deficits in balance and motor coordination, dystrophic neurites, swollen mitochondria, reduced number and caliber of motor neurons and hyperphosphorylated Tau (Chu et al., 2009). This phenotype suggests a broad effect in the regulation of the proteome. Additional studies, using 
the budding yeast, showed that, in fact, the Listerin homolog Ltn1 is involved in the mechanism of quality control of proteins, through association with the ribosomes (Bengtson and Joazeiro, 2010).

The UPS is also responsible of regulating social behavior and interaction. A role for the UPS in mouse models of Fragile X and Angelman Syndromes, two well-known forms of autism, was also unraveled recently. The defective degradation of PSD-95, a process required for synapse elimination, by the Mdm2 E3 ligase, may underlie the excessive dendritic spine number observed in Fragile X syndrome (Tsai et al., 2012). Reduced levels of the Ube3A protein levels, an E3 ligase, has also been associated with the Angelman Syndrome (Williams et al., 2010; Ebert and Greenberg, 2013). This protein is upregulated by synaptic activity thereby controlling the degradation of Arc, a protein involved in AMPAR endocytosis (Greer et al., 2010). Arc protein is also involved in the mGluRdependent long-term depression through AMPAR endocytosis (Waung et al., 2008), and its nuclear localization regulates homeostatic plasticity by decreasing GluA1 transcription (Korb et al., 2013). Knockout mouse models for Ube3A have reduced hippocampal synaptic GluA1 receptors with a concomitant decrease in AMPAR mediated current, and reduced levels of mESPC (Greer et al., 2010). More recently, conditional neuronal loss of Uba6, an E1 ligase involved in the specific activation of ubiquitin, was shown to induce hyperactivity, social interaction deficits, decreased spine density both in the amygdala and in the CA3 region, and impaired learning and memory in mice (Jin et al., 2007; Lee et al., 2013). Moreover, a more detailed biochemical analysis showed that the levels of Ube3A, Shank and Arc were elevated and decreased, respectively, in this mouse model (Lee et al., 2013). The reduced spine density is in accordance with other works showing that knockdown of Ube $3 \mathrm{~A}$ in pyramidal neurons reduces apical dendritic outgrowth (Miao et al., 2013). However, electrophysiological analysis of the synapses in this mouse model is still lacking.

\section{UPS in ischemic conditions}

Despite recent advances, there are still major gaps in the understanding of pathogenesis of cerebral ischemic injury and therapeutic options for stroke patients are limited (Moskowitz et al., 2010). Transient cerebral ischemia is associated with an inflammatory response and a rapid and excessive production of various misfolded proteins due to oxidative stress and other mechanisms (Ge et al., 2007, 2012). Overproduction of damaged proteins following ischemia is reflected in a pronounced increase of conjugation of targeted proteins with ubiquitin (Hayashi et al., 1992). Therefore, the accumulation of ubiquitin-containing protein aggregates following ischemia is a general feature. However, the factors leading to deposition of these aggregates and their consequences for stroke outcome remain poorly understood.

\subsection{UPS and in vivo ischemia models}

Transient cerebral ischemia induces irreversible misfolded protein aggregate formation. The first reports showed that brief rat forebrain ischemia, induced by bilateral common carotid occlusion combined with a reduction of the mean arterial blood pressure to $50 \mathrm{mmHg}$, evoked a selective and sustained loss of ubiquitin immunoreactivity in rat hippocampal CA1 neurons (Magnusson and Wieloch, 1989). However, a few years later, it was shown that the loss of ubiquitin immunoreactivity in gerbil hippocampal CA1 neurons after ischemia induced by bilateral carotid occlusion (BCO) was a result of free ubiquitin depletion and did not arise from ubiquitin conjugation (Morimoto et al., 1996). It was also shown that BCO-induced transient ischemia in gerbils promotes a transient consumption of free ubiquitin associated with an increase of conjugated multiubiquitin chains in hippocampal CA3 and dentate gyrus regions, where neurons survive, but these changes are persistent in the CA1 region, where neurons are more vulnerable and destined to die after $5 \mathrm{~min}$ of ischemia (Ide et al., 1999). Under the same experimental conditions, a transient upregulation of the ubiquitin mRNA was observed in all hippocampal neurons and in the cerebral cortex, with maximal effects observed after $6 \mathrm{~h}$ of reperfusion, which then decreased to control levels at $48 \mathrm{~h}$ (Ide et al., 1999). In a two-vessel transient occlusion model of global ischemia in rats, dying neurons in the hippocampal CA1 region also exhibited an accumulation of highmolecular weight ubiquitin-conjugated proteins, which were found in clusters around nuclei and close to the dendritic membrane during 4-24 h reperfusion after $15 \mathrm{~min}$ ischemia; this was not observed in CA1 neurons destined to survive or in the dentate gyrus (Hu et al., 2000). Similar results were obtained at 1 , 4 , and $24 \mathrm{~h}$ of reperfusion after $2 \mathrm{~h} \mathrm{MCAO}$ in rats, a model of focal ischemia (Hu et al., 2001). The ubiquitin-positive immunoclusters of misfolded/damaged protein aggregates were also found in postsynaptic densities from hippocampal neurons of rats subjected to $15 \mathrm{~min}$ of two-vessel occlusion model followed by 4 and $24 \mathrm{~h}$ of reperfusion (Liu et al., 2004). Moreover, selective accumulation of $\mathrm{UBB}^{+1}$, a mutant ubiquitin that is formed by dinucleotide deletion in mRNA, causing misreading and production of an aberrant Cterminus ubiquitin (van Den Hurk et al., 2001), which cannot ubiquitinate target proteins, was also found in the cytoplasm of CA1 neurons of gerbils submitted to 5 min of bilateral common carotid arteries occlusion and reperfusion (Yamashiro et al., 2007). This accumulation appeared at $30 \mathrm{~min}$ after ischemia in CA1 region and increased up to day 4 after ischemia. The number of neurons displaying $\mathrm{UBB}^{+1}$ accumulation was also increased from $30 \mathrm{~min}$ to $6 \mathrm{~h}$ after ischemia (Yamashiro et al., 2007). These changes were found to precede neuronal death in the hippocampal CA1 region. $\mathrm{UBB}^{+1}$ protein was also transiently expressed but did not accumulate in the surviving neurons of the CA3 region, dentate gyrus, and frontal cortex, suggesting that accumulation of $\mathrm{UBB}^{+1}$ is specifically related to delayed neuronal death of CA1 neurons (Yamashiro et al., 2007). Since $\mathrm{UBB}^{+1}$ can act as an endogenous proteasome inhibitor (Lindsten et al., 2002), these observations further point to a proteasomal dysfunction in the hippocampal CA1 region after ischemia and reperfusion. In summary, these results suggest that ubiquitin-containing clusters of misfolded or damaged proteins are formed in all post-ischemic neurons, primarily during reperfusion. A recent study suggested that the 15-deoxy$\Delta^{12,14}$-prostaglandin $\mathrm{J} 2\left(15 \mathrm{~d}-\mathrm{PHJ}_{2}\right)$ produced by a cyclooxygenasedependent mechanism after rat transient focal brain ischemia may contribute to the aggregation of ubiquitinated proteins (Liu et al., 2013). Accordingly, addition of $15 \mathrm{~d}-\mathrm{PHJ}_{2}$ to cultures cerebrocortical neurons induced the accumulation and aggregation of ubiquitinated proteins and downregulated the activity of the proteasome (Liu et al., 2013).

The clusters of ubiquitinated proteins formed after brain ischemia may give rise to protein aggregates by an unknown process, possibly through translation arrest, but the aggregates are maintained exclusively in CA1 neurons until their death (Hu et al., 2000, 2001; Liu et al., 2004, 2005). In fact, translational complex components are irreversibly clumped into large abnormal protein aggregates after transient brain ischemia (Liu et al., 2005) or focal brain ischemia (Zhang et al., 2006a), suggesting that the irreversible inhibition of translation in neurons destined to die after ischemia is caused by irreversible aggregation of translational complex components, chaperones and protein folding enzymes. Moreover, proteasomes, particularly the 19S RP, are also sequestered into these protein aggregates in post-ischemic brains ( $\mathrm{Ge}$ et al., 2007). Furthermore, cytoplasmic ubiquitin-containing 
aggregates and stress granules are clustered together in CA1 neurons at day 2-3 of reperfusion following global forebrain ischemia and may contribute to sustained translation arrest and CA1 pyramidal neuron vulnerability (DeGracia et al., 2007).

Recent work also demonstrates that reperfusion rather than ischemia leads to the accumulation of ubiquitin aggregates in the neocortex, an area of more intense reperfusion, as well as in the striatum after transient focal ischemia (MCAO) (Hochrainer et al., 2012). However, no ubiquitin aggregates were found in permanent ischemia and surprisingly proteasome impairment was greatest under these conditions (Hochrainer et al., 2012), suggesting that the two events are independent. Alternatively, the absence of ubiquitin aggregates under the latter conditions may be attributed to ATP depletion, which should prevent the activation of ubiquitin by the ATP-dependent E1 ligase, thereby reducing protein ubiquitination (Huang et al., 2013). Taken together, the available evidence suggests that the formation of ubiquitin-protein aggregates may reflect a greater potential for tissue survival in the immediate postischemic period (Fig. 4). The cause and effect relationship between protein aggregation and subsequent neuronal death still remains to be determined and further studies are needed to uncover the roles of ubiquitinated protein aggregation after brain ischemia.

Accumulation of ubiquitin conjugated proteins and depletion of free ubiquitin following an ischemic injury suggest impairment of proteasome function. In fact, transient global brain ischemia impairs 26S proteasome function by promoting proteasome disassembly, both in rats (Ge et al., 2007) and gerbils (Kamikubo and Hayashi, 1996; Asai et al., 2002). However, while the 26S proteasome activity recovers in many regions after reperfusion (e.g. CA3, dentate gyrus, and frontal cortex), in more vulnerable areas, such as CA1 region of the hippocampus, the 19S and 20S proteasomes do not fully reassociate, and the proteasome is irreversibly inhibited (Asai et al., 2002). A time-dependent decrease in proteasome activity has also been detected in ipsilateral cortex and hippocampus during 1-24 h reperfusion after transient focal ischemia (Keller et al., 2000), and this downregulation of proteasome activity was partly attributed to oxidative stress (Keller et al., 2000). Furthermore, it was shown that proteasomes are disassembled after an episode of global brain ischemia, partially because of ATP depletion (Fig. 4) (Asai et al., 2002). It remains to be determined why the ATP-dependent reassembly of $26 \mathrm{~S}$ proteasome is selectively impaired in the hippocampal CA1 region.

Transient forebrain ischemia induced by bilateral common artery occlusion in Mongolian gerbils and transient focal brain ischemia induced by MCAO in mice were without effect on the expression of proteasome subunits, although a downregulation of the proteasome activity was found in both cases (Kamikubo and Hayashi, 1996; Keller et al., 2000). These evidences suggest that posttranslational mechanisms are involved in the downregulation of the proteasome in the ischemic brain. Transient focal cerebral

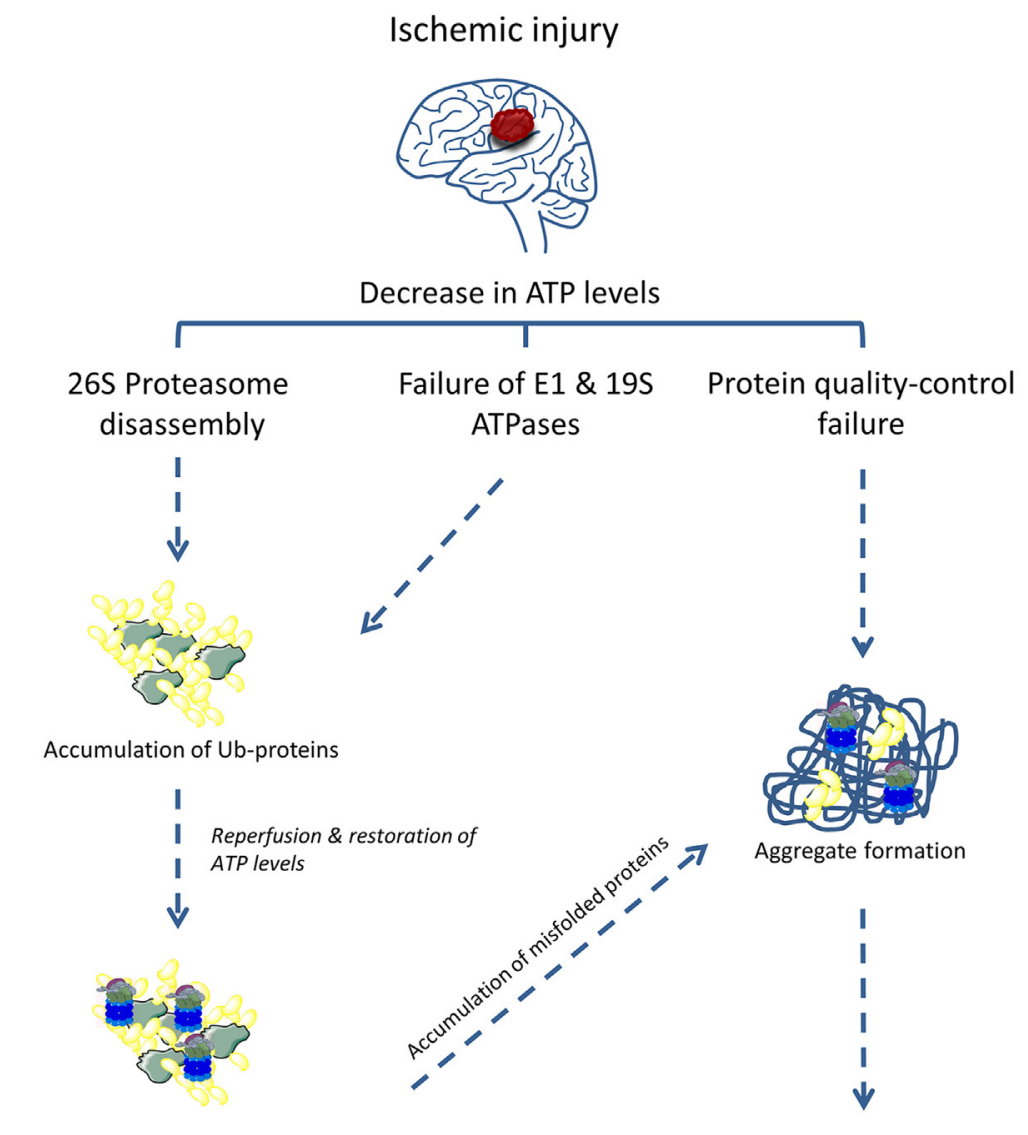

Sequestration of 265 proteasome $\&$ Proteasome blockade

Neuroprotective strategy

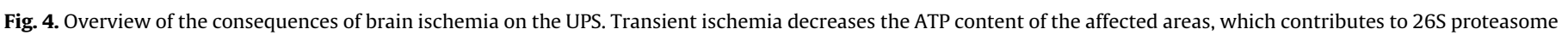

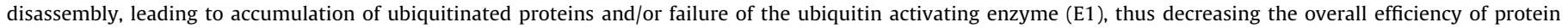

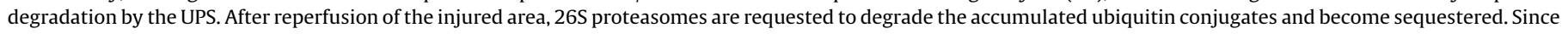

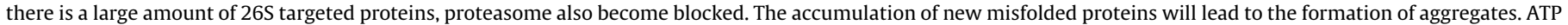

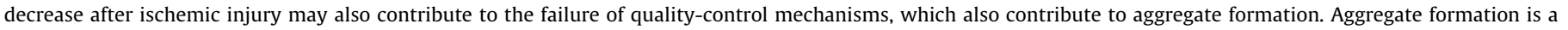
protective response of the cell against abnormal proteins. 
ischemia in mice was also shown to upregulate the expression of immunoproteasomal subunits (LMP2 and LMP7), both in the nuclear and cytosolic compartments. These alterations were mainly observed in neurons and considering that the i-proteasome displays an increased proteolytic activity (van Deventer and Neefjes, 2010) it may contribute to the recovery of the proteasome activity following the ischemic insult. This delayed response may increase tolerance to transient ischemia by allowing the clearance of unwanted proteins.

In summary, brain ischemia induces an excessive accumulation of ubiquitinated proteins, which are in excess to be degraded by the proteasome (Fig. 4). The accumulation of ubiquitinated proteins is further increased due to the impairment of the proteasome activity, giving rise to aggregates that also contain other unfolded/damaged proteins or organelles, as observed in delayed neuronal death after brain ischemia.

\subsection{Changes in the UPS in in vitro models of global ischemia}

OGD, an in vitro model for transient global ischemia, was shown to induce hippocampal neuronal death, through activation of NMDA receptors, and to downregulate proteasome activity in a NMDA receptor activation-dependent manner (Caldeira et al., 2013). This OGD-induced decline on proteasome activity may be due to a rapid ATP depletion. A decrease in ATP content was in fact observed in cultured cortical neurons subjected to OGD followed by reoxygenation (Chen et al., 2010) and in cultured hippocampal neurons subjected to excitotoxic stimulation (see Section 4.3) (Caldeira et al., 2013). However, irreversible ATP-independent inhibition of proteasome activity was detected in hippocampal CA1 neurons after transient forebrain ischemia (Asai et al., 2002), suggesting that two different mechanisms may be involved in the regulation of proteasome activity after OGD.

OGD followed by incubation in culture conditioned medium (to mimic reperfusion) induces protein oxidative damage in cultured cortical neurons. The upregulation in oxidized proteins is coupled to an increase in protein degradation, both during and after OGD (Weih et al., 2001). Inhibition of the proteasome was shown to prevent proteolysis of oxidized proteins after OGD, suggesting a role for the UPS in the clearance of oxidized proteins in neuronal cells. Moreover, proteasomal activity was found to be similar immediately after OGD and in sham-washed cultured cortical neurons (Weih et al., 2001), in agreement with the relative resistance of the proteasome against oxidative stress (Reinheckel et al., 1998). However, these results contrast with the protein aggregation and reduced cytosolic and nuclear free ubiquitin distribution reported in the organotypic hippocampal slice culture model of OGD (Ouyang et al., 2005). OGD followed by reoxygenation induced a time-dependent ubiquitination of misfolded proteins and aggregate formation, specially clustered near nuclei of cultured cortical neurons (Chen et al., 2010). These effects seem to be mediated by a dysregulation of endoplasmic reticulum $\mathrm{Ca}^{2+}$ concentration, which affects protein folding. Interestingly, endoplasmic reticulum $\mathrm{Ca}^{2+}$ dysregulation also partially affects proteasome activity after OGD (Chen et al., 2010). These findings point to the UPS as an active component of the cellular defense system against oxidative stress after cerebral ischemia.

\subsection{UPS in glutamate-induced excitotoxicity}

Activation of NMDA receptors plays a role in neuronal death induced by transient OGD in different neuronal culture systems (Martinez-Sanchez et al., 2004; Bonde et al., 2005; Ahlgren et al., 2011; Caldeira et al., 2013), similarly to the role of glutamate receptors in neuronal damage in the ischemic brain [for review (Kostandy, 2012)]. The activation of NMDA-type glutamate receptors is likely to be a mediator in OGD and ischemia-induced downregulation of the proteasome activity, as shown in experiments where cultured hippocampal neurons were subjected to excitotoxic stimulation with glutamate or with NMDA (Caldeira et al., 2013). The downregulation of the proteasome activity after excitotoxic stimulation with glutamate is specifically mediated by activation of extrasynaptic NMDA receptors (Caldeira et al., 2013), in agreement with their role in excitotoxic neuronal death (Bengtson et al., 2008). In particular, the entry of calcium through NMDAR channels is actively involved in the downregulation of the proteasome activity, possibly due to activation of downstream signaling pathways that target proteasome proteolytic activity. The effects of excitotoxic stimulation with glutamate on the activity of the proteasome, as measured with fluorogenic substrates after native gel electrophoresis, correlate with a disassembly of the $26 \mathrm{~S}$ proteasome, by a mechanism that may be related with the decrease in the ATP content (Caldeira et al., 2013). These structural changes in the proteasome resemble the alterations in the proteasome structure observed in brain ischemia (Kamikubo and Hayashi, 1996; Asai et al., 2002; Ge et al., 2007), further suggesting that overactivation of glutamate receptors plays a key role in the downregulation of the proteasome in the ischemic brain.

Although it is still unknown which are the signaling cascades that mediate the downregulation of the proteasome activity in brain ischemia, the activation of calpains and lysosomal cathepsins are good candidates, given the fact that the toxic effects of glutamate are partially mediated by the $\mathrm{Ca}^{2+}$-dependent activation of calpains (Takano et al., 2005) and both proteases were shown to be activated before downregulation of the proteasome in hippocampal neurons subjected to excitotoxic stimulation (Melo et al., 2013). Accordingly, a recent study showed a calpainmediated cleavage of the Rpn10 protein in cultured cortical neurons with compromised ATP production, and the cleavage of this subunit may affect the assembly of the $26 \mathrm{~S}$ proteasome (Huang et al., 2013). The lysosomal cysteine proteases, cathepsin-B and cathepsin-L are also involved in ischemic cerebral damage (Seyfried et al., 2001) and in proteasomal subunit degradation (Cuervo et al., 1995). This is in agreement with the results showing that the excitotoxicity-induced proteasome inhibition is partially prevented by inhibition of cathepsin-L (Caldeira et al., 2013). Taken together, these results suggest a cross-talk between different families of proteases and the proteasome which is likely to regulate the cell fate (Sun et al., 2004; Stoehr et al., 2013).

The studies on the effect of excitotoxic stimulation on the activity of the proteasome showed a preferential targeting of nuclear proteasomes in cultured hippocampal neurons (Caldeira et al., 2013), but the differential effects when compared with the cytoplasmic population of proteasomes are still not understood. In addition to the changes in the activity of the proteasome, excessive NMDAR stimulation in cultured cortical neurons was also shown to induce hyperphosphorylation of the Anaphase-Promoting complex/cyclosome (APC/C) Cdh1 activator protein, which leads to a cytosolic accumulation of this E3 ligase responsible for the control of cell cycle progression (Peters, 2002; Maestre et al., 2008). The effect of excitotoxic stimulation is mediated by calpain cleavage of cyclin-dependent kinase-5 (Cdk5), with formation of a p25 product that induces the hyperphosphorylation of Cdh1 (Maestre et al., 2008). In this case, the downregulation of the E3 ligase in the nucleus allows the accumulation of cyclin B1 in this compartment, thus inducing apoptotic cell death by abnormal entry in S-phase (Almeida et al., 2005; Maestre et al., 2008). Excitotoxic stimulation with glutamate also downregulated total DUB activity in cultured hippocampal neurons although no effect was observed on the activity of Uch-L1, showing that not all deubiquitinating enzymes are affected (Caldeira et al., 2013). Together, these results suggest 
that the UPS is subjected to regulation at different levels in brain ischemia, and differential effects may be expected in distinct subcellular compartments.

Given the evidences pointing to a role of the UPS in the regulation of glutamatergic synapses (see Section 3.2), the downregulation of the proteasome observed in brain ischemia may have important implications at this level. A neurotoxic insult with glutamate ( $100 \mu \mathrm{M}$ during $4 \mathrm{~h}$ ) was shown to decrease the number of PDS-95 puncta and to cause PSD loss, which was accompanied by spine loss in cultured hippocampal neurons (Waataja et al., 2008). These effects were attenuated by NMDA receptor antagonists, but protective effects were also observed in the presence of a proteasome inhibitor and by a genetic approach expressing p14ARF (which binds and inhibits mdm2, an E3 ligase known to ubiquitinate PSD-95, targeting the protein for proteasomal degradation). This study suggests that glutamate activates NMDA receptors to stimulate $\mathrm{a} \mathrm{Ca}^{2+}$-dependent $\mathrm{E} 3$ ligase leading to PSD-95 ubiquitination and degradation by the proteasome, with consequent loss of PSD-95 clustering (Waataja et al., 2008). Taken together, these evidences suggest that some of the alterations resulting from proteasome inhibition in brain ischemia may actually be protective. Accordingly, proteasome and calpain inhibition did protect the neuronal markers for dendrites (MAP2 ), axons (Neurofilament-H) and the vesicular glutamate transporters (VGLUT1-2) in cultured hippocampal neurons subjected to excitotoxic stimulation (Melo et al., 2013).

Brain ischemia also has a strong impact in GABAergic neurotransmission, and in particular the downregulation in the postsynaptic expression of $\mathrm{GABA}_{\mathrm{A}}$ receptors largely contributes to a decrease in inhibitory activity. Excitotoxic stimulation with glutamate was shown to induce UPS-dependent cleavage of glutamic acid decarboxylase (GAD; GAD65/67), the enzyme involved in the synthesis of GABA, in cultured hippocampal neurons (Baptista et al., 2010). GAD cleavage decreased enzyme activity and changed the subcellular distribution of GAD65 (Baptista et al., 2010). These alterations are expected to decrease GABA production and to downregulate GABAergic synaptic transmission, thereby contributing to neuronal death.

Taken together, the available evidences show that excitotoxic stimulation with glutamate has multiple effects on the ubiquitinproteasome system which may contribute to the demise process in brain ischemia and in other neurological disorders.

\subsection{UPS in ischemic tolerance}

Ischemic tolerance is a neuroprotective mechanism in brain, whereby prior exposure to a brief non-toxic ischemic event induces protection to subsequent normal harmful ischemic insult (for review see Meller, 2009). Two mechanisms of ischemic tolerance have been described: (i) classical or delayed ischemic tolerance, which requires protein synthesis and changes in the genomic response, resulting in protection after $24-72 \mathrm{~h}$ after the preconditioning stimulus (Barone et al., 1998), and (ii) rapid ischemic tolerance, independent of new protein synthesis and producing neuroprotection within $30 \mathrm{~min}$ to $1 \mathrm{~h}$ following the preconditioning event (Meller et al., 2006), suggesting a role for posttranslational mechanisms (for review Meller, 2009).

UPS has been shown to play an important role in both types of ischemic tolerance. In fact, after delayed ischemic tolerance (5 min of bilateral common carotid artery occlusion at $48 \mathrm{~h}$ of reperfusion after a preconditioning stimulus of $2 \mathrm{~min}$ ) the abundance of free ubiquitin was found to be restored above the normal values, in contrast with the ischemia-induced moderate and transient reduction of free ubiquitin. Although the results suggest de novo ubiquitin synthesis, no changes were observed in the ubiquitin mRNA (Ide et al., 1999). A role of UPS on rapid tolerance to ischemia was also described. A proteomic analysis (using ubiquitin pulldown assay and mass spectrometry) of ubiquitinated proteins showed an upregulation of 17 proteins in cultured cerebrocortical neurons after a preconditioning ischemic event in vitro (OGD-pretreated cells) and 7 proteins were exclusive of control samples. Moreover, it was shown that a cell death-associated protein, Bcl-2interacting mediator of cell death (Bim), is selectively ubiquitinated and degraded by the proteasome in cultured cortical neurons preconditioned with $30 \mathrm{~min}$ of OGD and $1 \mathrm{~h}$ of recovery followed by $120 \mathrm{~min}$ of OGD and $24 \mathrm{~h}$ of post-incubation in culture conditioned medium (Meller et al., 2006). These results suggest a rapid degradation of cell death promoting proteins and rapid neuroprotection by the UPS. Moreover, the UPS was found to increase neuronal resistance to excitotoxicity through rapid modulation of postsynaptic densities after preconditioning ischemia (Meller et al., 2008). Ubiquitination and degradation of proteins involved in the structure and function of PSD, namely MARCKS (myristoylated, alanine-rich C-kinase substrate) and fascin (actin binding proteins), result in the reorganization of actin cytoskeleton after preconditioning ischemia. These alterations result in the loss of NMDAR from the PSD and a concomitant selective attenuation of toxic NMDAR-mediated signaling at the time when tolerance to ischemia is acquired (Meller et al., 2008). Accordingly, inhibition of proteasome activity was found to block the rapid ischemic tolerance-induced neuroprotection (Meller et al., 2008). Accordingly, activation of NMDA receptors was shown to induce PSD-95 degradation by the UPS, together with a loss of dendritic spines, in cultured cerebrocortical neurons (Waataja et al., 2008). The neuroprotective effects (cerebral infarct size, memory and motor performance) induced by both acute and delayed ischemia preconditioning are also attenuated when the proteasome is inhibited with Z-Leu-Leu-Phe-CHO (Rehni et al., 2010), further suggesting that immediate as well as prolonged beneficial effects of ischemic preconditioning in global cerebral ischemia and reperfusion (17 min BCAO followed by $24 \mathrm{~h}$ reperfusion) may be attributed to UPS activity.

A recent report showed that ischemic postconditioning (three cycles of $30 \mathrm{~s}$ reperfusion and $30 \mathrm{~s}$ reocclusion after $2 \mathrm{~h}$ of MCAO in rat) can be neuroprotective, since it decreases the size of cerebral infarction and increases the activities of superoxide dismutase catalase and proteasome, thereby decreasing the levels of oxidized proteins and downregulating the formation of cytotoxic protein aggregates (Li et al., 2012). Moreover, ischemic postconditioning was also found to have a protective effect on hippocampal CA1 neurons (Liang et al., 2012). In this study, ischemic postconditioning ( $15 \mathrm{~min}$ of two vessel occlusion transient global ischemia followed by three cycles of $30 \mathrm{~s}$ reperfusion and $30 \mathrm{~s}$ clamping in rat) prevented neuronal death in the hippocampal CA1 region caused by transient ischemia and reperfusion (Liang et al., 2012). This effect was accompanied by a decrease in ubiquitin containing aggregates and partial inhibition of the effects of ischemia/ reperfusion on the proteasome activity and abundance (Liang et al., 2012), suggesting that ischemic postconditioning rescued neuronal death in the hippocampal CA1 region by suppressing the formation of protein aggregates.

\subsection{Protective effects of proteasome modulators in brain ischemia}

The experimental evidence described in Sections 4.1 and 4.2 point to a downregulation of the UPS in brain ischemia, as observed for example by an increase in the accumulation of ubiquitinated proteins, which correlates with neuronal death. Furthermore, injection of a proteasome inhibitor into the lateral ventricle of rats significantly decreased NF- $\mathrm{KB}$ activity and resulted in apoptotic neuronal death in various CNS areas, suggesting that proteasome inhibition induces apoptotic neuronal death (Taglialatela et al., 
1998). Also, incubation of different types of neurons with proteasome inhibitors was shown to induce cell death (Keller and Markesbery, 2000; Qiu et al., 2000; Bobba et al., 2002; Ding et al., 2006). These results would further suggest that proteasome inhibition contributes to neuronal death in brain ischemia. However, in contrast with the evidence described above, proteasome inhibitors were shown to provide neuroprotection in various models of stroke.

CVT-634, the first proteasome inhibitor to be tested in a rat model of focal brain ischemia, reduced infarction without affecting regional cerebral blood flow (Buchan et al., 2000). A more detailed characterization of the neuroprotective properties of proteasome inhibitors in brain ischemia was provided with studies using MLN519 (previously named PS519), a compound structurally similar to lactacystin (Williams et al., 2003). The effect of MLN519 was tested using transient MCAO (Phillips et al., 2000; Williams et al., 2003, 2004, 2005) and the cardioembolic stroke model (Zhang et al., 2001), and a therapeutic window of 6-10 h after ischemia/reperfusion brain injury was observed using the former model. The neuroprotective effects of MLN519 were attributed to a decrease in inflammation after the ischemic injury, through downregulation of NF- $\mathrm{BB}$ and downstream inflammatory genes, as well as inhibition of the infiltration of inflammatory cells into the brain. The effects of the proteasome inhibitor were observed on the 'early' and 'delayed' inflammatory responses after the ischemic injury, characterized by neutrophil infiltration and macrophage invasion, respectively, even with delayed treatments (Phillips et al., 2000; Zhang et al., 2001; Berti et al., 2003; Williams et al., 2003 , 2004). A detailed immunohistochemical analysis of the cells showing an increase in NF- $\kappa$ B immunoreactivity after transient MCAO, showed the highest levels in leukocytes and endothelial cells, but this effect was significantly reduced upon administration of MLN519 (Williams et al., 2003). Furthermore, intravenous administration of MLN519 significantly downregulated cell adhesion molecules, particularly in endothelial cells (Berti et al., 2003). Considering the cell specific effects of MLN519 and its relatively poor penetration across the blood-brain barrier (BBB), it was suggested that the effects of proteasome inhibition in brain ischemia may be mediated primarily at the BBB to interfere with the penetration of inflammatory cells (Phillips et al., 2000). In fact, proteasome inhibitors may also act directly on leucocytes to prevent their entry into the brain (Williams et al., 2004).

In addition to the effects in reducing the brain pathology, MLN519 also improved the neurological outcome after MCAO (Phillips et al., 2000; Zhang et al., 2001; Williams et al., 2003, 2005). Furthermore, when combined with tissue plasminogen activator (tPA), MLN519 reduced the infarct volume and improved the neurological outcome as determined 1 week after stroke (Zhang et al., 2001). Similarly, the proteasome inhibitor bortezomib combined with low doses of tPA showed additional neuroprotective effects when tested in a model of embolic stroke in rats (Zhang et al., 2006b, 2010). Single administration of bortezomib within 2$4 \mathrm{~h}$ after injury also showed neuroprotective effects, and the proteasome inhibitor was proposed to act by promoting eNOSdependent vascular protection and to prevent NF-кB-dependent vascular disruption (Zhang et al., 2006b,c, 2010).

Although bortezomib has been approved by the Food and Drug Administration for the treatment of multiple myeloma and mantle cell lymphoma, the clinical use of this proteasome inhibitor is limited because of severe side effects (Ruschak et al., 2011). A novel proteasome inhibitor, BSc2118, which is putatively better tolerated, was shown to provide protection in mice subjected to intraluminal MCAO, when injected intrastriatally no later than $12 \mathrm{~h}$ post-stroke. A single injection of BSc2118 provided long-term neuroprotection, reduced functional impairment, stabilized the blood-brain barrier by decreasing MMP9 activity and enhanced angioneurogenesis. The upregulation of the HIF1A transcription factor is also an important mediator in BSc2118-induced neuroprotection (Doeppner et al., 2012). Furthermore, BSc2118 treatment increased the levels of erythropoietin, brain-derived neurotrophic factor and vascular endothelial growth factor, suggesting that the proteasome inhibitor may provide acute neuroprotection in addition to enhancing brain remodeling (Doeppner et al., 2012).

The apparent contradiction between the neuronal death resulting from proteasome inhibition and the effect of proteasome inhibitors in brain ischemia may be explained by an effect of proteasome inhibition in the secondary phase of brain injury and in neuroinflammation after stroke, which are reduced by these compounds. Although neurons are sensitive to proteasome inhibition, they may be able to tolerate relatively long periods of intracellular accumulation of ubiquitinated proteins, allowing the control of neuroinflammation with the proteasome inhibitors.

The recent development of small molecule inhibitors of deubiquitinating enzymes (USP and other classes of DUBs), which stabilize the polyubiquitin chains bound to their specific targets and thereby promote their degradation, will allow testing the effect of upregulating the proteasome activity on ischemiainduced neuronal damage. From the experimental and clinical points of view, these molecules will benefit from the specificity of each one of the USP. A recent study reported the effect of IU1, which acts as a Usp14 inhibitor, a DUB that acts as a negative regulator of the 26S proteasome (Lee et al., 2010), on transient focal cerebral ischemia induced by MCAO. Administration of IU1 1 day before MCAO significantly reduced the infarct volume, when determined 4 days after the lesion. In this case the effects of IU1 were correlated with the control of REST protein levels, which is known to increase in ischemic neurons destined to die (Doeppner et al., 2013). However, it remains to be determined whether IU1 is also neuroprotective when administered after the ischemic injury. The upregulation of protein degradation by the proteasome in the presence of IU1 may compensate for the toxic effects resulting from a downregulation of the proteasome activity in brain ischemia. However, additional studies should be performed to investigate the cellular and molecular mechanisms of neuroprotection by this DUB inhibitor.

\section{Conclusions}

The available evidence clearly point to a role of excitotoxic damage in ischemia-induced downregulation of the proteasome activity, which may contribute to neuronal death. However, at this point we have a limited understanding of the effect of brain ischemia on the other components of the UPS, in particular ligases and deubiquitinases, which should have an impact on the abundance of their target proteins. The results showing distinct effects of excitotoxic cell damage on the activity of the proteasome in the nuclear and cytosolic compartments also suggest that UPS targets may be differentially affected in brain ischemia depending on their location in the cell. In particular, alterations in the UPS in the nuclear compartment may affect the activity of transcription factors, thereby altering gene expression. Given the role of the UPS in synaptic regulation, alterations in the proteasome activity may also lead to changes in the activity of excitatory and inhibitory synapses. Although proteasome inhibitors have been shown to provide protection in brain ischemia, alternative strategies, specifically targeting the molecular mechanisms responsible for neuroinflammation, are likely to provide better results since they would avoid exacerbating the problems arising from the stroke-induced downregulation of the proteasome. The future development of small molecule inhibitors of deubiquitinating ubiquitin-specific proteases (USP) (Zhang et al., 2013b) and other 
deubiquitinating enzymes (Tan et al., 2008) will also allow modifying in a more specific manner the abundance of protein targets of the UPS and may prove to be useful as neuroprotective strategies in brain ischemia. Furthermore, although proteasome inhibitors and activators have shown neuroprotective effects in cerebral ischemia the detailed biochemical alterations in the ubiquitin-modified landscape after ischemia remain to be elucidated.

\section{Acknowledgements}

The work in the authors laboratory is funded by Fundação para a Ciência e Tecnologia, COMPETE (Programa Operacional Factores de Competitividade), QREN and FEDER (Fundo Europeu de Desenvolvimento Regional) (PTDC/SAU-NMC/120144/2010, PTDC/NEUNMC/0198/2012 and PEst-C/SAU/LA0001/2011).

\section{References}

Aarts, M., Iihara, K., Wei, W.L., Xiong, Z.G., Arundine, M., Cerwinski, W., MacDonald, J.F., Tymianski, M., 2003. A key role for TRPM7 channels in anoxic neuronal death. Cell 115, 863-877.

Adhami, F., Schloemer, A., Kuan, C.Y., 2007. The roles of autophagy in cerebral ischemia. Autophagy 3, 42-44.

Ahlgren, H., Henjum, K., Ottersen, O.P., Runden-Pran, E., 2011. Validation of organotypical hippocampal slice cultures as an ex vivo model of brain ischemia: different roles of NMDA receptors in cell death signalling after exposure to NMDA or oxygen and glucose deprivation. Cell Tissue Res. 345, 329-341.

Almeida, A., Bolanos, J.P., Moreno, S., 2005. Cdh1/Hct1-APC is essential for the survival of postmitotic neurons. J. Neurosci. 25, 8115-8121.

Aoki, M., Tamatani, M., Taniguchi, M., Yamaguchi, A., Bando, Y., Kasai, K., Miyoshi, Y., Nakamura, Y., Vitek, M.P., Tohyama, M., Tanaka, H., Sugimoto, H., 2001. Hypothermic treatment restores glucose regulated protein 78 (GRP78) expression in ischemic brain. Brain Res. Mol. Brain Res. 95, 117-128.

Araujo, I.M., Verdasca, M.J., Leal, E.C., Bahr, B.A., Ambrosio, A.F., Carvalho, A.P., Carvalho, C.M., 2004. Early calpain-mediated proteolysis following AMPA receptor activation compromises neuronal survival in cultured hippocampal neurons. J. Neurochem. 91, 1322-1331.

Asai, A., Tanahashi, N., Qiu, J.H., Saito, N., Chi, S., Kawahara, N., Tanaka, K., Kirino, T., 2002. Selective proteasomal dysfunction in the hippocampal CA1 region after transient forebrain ischemia. J. Cereb. Blood Flow Metab. 22, $705-710$.

Bano, D., Young, K.W., Guerin, C.J., Lefeuvre, R., Rothwell, N.J., Naldini, L., Rizzuto, R., Carafoli, E., Nicotera, P., 2005. Cleavage of the plasma membrane $\mathrm{Na}^{+} / \mathrm{Ca}^{2+}$ exchanger in excitotoxicity. Cell 120, 275-285.

Baptista, M.S., Melo, C.V., Armelao, M., Herrmann, D., Pimentel, D.O., Leal, G., Caldeira, M.V., Bahr, B.A., Bengtson, M., Almeida, R.D., Duarte, C.B., 2010. Role of the proteasome in excitotoxicity-induced cleavage of glutamic acid decarboxylase in cultured hippocampal neurons. PLoS One 5, e10139.

Barone, F.C., White, R.F., Spera, P.A., Ellison, J., Currie, R.W., Wang, X., Feuerstein, G.Z., 1998. Ischemic preconditioning and brain tolerance: temporal histological and functional outcomes, protein synthesis requirement, and interleukin-1 receptor antagonist and early gene expression. Stroke 29, 1937-1950.

Baumeister, W., Walz, J., Zuhl, F., Seemuller, E., 1998. The proteasome: paradigm of a self-compartmentalizing protease. Cell 92, 367-380.

Beck, P., Dubiella, C., Groll, M., 2012. Covalent and non-covalent reversible proteasome inhibition. Biol. Chem. 393, 1101-1120.

Beltrao, P., Albanese, V., Kenner, L.R., Swaney, D.L., Burlingame, A., Villen, J., Lim, W.A., Fraser, J.S., Frydman, J., Krogan, N.J., 2012. Systematic functional prioritization of protein posttranslational modifications. Cell 150, 413-425.

Bengtson, C.P., Dick, O., Bading, H., 2008. A quantitative method to assess extrasynaptic NMDA receptor function in the protective effect of synaptic activity against neurotoxicity. BMC Neurosci. 9, 11

Bengtson, M.H., Joazeiro, C.A., 2010. Role of a ribosome-associated E3 ubiquitin ligase in protein quality control. Nature 467, 470-473.

Berti, R., Williams, A.J., Velarde, L.C., Moffett, J.R., Elliott, P.J., Adams, J., Yao, C., Dave, J.R., Tortella, F.C., 2003. Effect of the proteasome inhibitor MLN519 on the expression of inflammatory molecules following middle cerebral artery occlusion and reperfusion in the rat. Neurotoxicol. Res. 5, 505-514.

Bevers, M.B., Neumar, R.W., 2008. Mechanistic role of calpains in postischemic neurodegeneration. J. Cereb. Blood Flow Metab. 28, 655-673.

Bingol, B., Schuman, E.M., 2006. Activity-dependent dynamics and sequestration of proteasomes in dendritic spines. Nature 441, 1144-1148.

Bingol, B., Wang, C.F., Arnott, D., Cheng, D., Peng, J., Sheng, M., 2010. Autophosphorylated CaMKIIalpha acts as a scaffold to recruit proteasomes to dendritic spines. Cell 140, 567-578.

Bobba, A., Canu, N., Atlante, A., Petragallo, V., Calissano, P., Marra, E., 2002. Proteasome inhibitors prevent cytochrome $c$ release during apoptosis but not in excitotoxic death of cerebellar granule neurons. FEBS Lett. 515, 8-12.
Bonde, C., Noraberg, J., Noer, H., Zimmer, J., 2005. Ionotropic glutamate receptors and glutamate transporters are involved in necrotic neuronal cell death induced by oxygen-glucose deprivation of hippocampal slice cultures. Neuroscience 136, 779-794.

Boutet, S.C., Disatnik, M.H., Chan, L.S., Iori, K., Rando, T.A., 2007. Regulation of Pax3 by proteasomal degradation of monoubiquitinated protein in skeletal muscle progenitors. Cell 130, 349-362.

Boyce, M., Yuan, J., 2006. Cellular response to endoplasmic reticulum stress: a matter of life or death. Cell Death Differ. 13, 363-373.

Braun, B.C., Glickman, M., Kraft, R., Dahlmann, B., Kloetzel, P.M., Finley, D., Schmidt, M., 1999. The base of the proteasome regulatory particle exhibits chaperonelike activity. Nature Cell Biol. 1, 221-226.

Brooks, P., Murray, R.Z., Mason, G.G., Hendil, K.B., Rivett, A.J., 2000. Association of immunoproteasomes with the endoplasmic reticulum. Biochem. J. 352 (Pt. 3) 611-615.

Broughton, B.R., Reutens, D.C., Sobey, C.G., 2009. Apoptotic mechanisms after cerebral ischemia. Stroke 40, e331-e339.

Buchan, A.M., Li, H., Blackburn, B., 2000. Neuroprotection achieved with a novel proteasome inhibitor which blocks NF-kappaB activation. Neuroreport 11,427430.

Cajigas, I.J., Will, T., Schuman, E.M., 2010. Protein homeostasis and synaptic plasticity. EMBO J. 29, 2746-2752.

Caldeira, M.V., Curcio, M., Leal, G., Salazar, I.L., Mele, M., Santos, A.R., Melo, C.V Pereira, P., Canzoniero, L.M., Duarte, C.B., 2013. Excitotoxic stimulation downregulates the ubiquitin-proteasome system through activation of NMDA receptors in cultured hippocampal neurons. Biochim. Biophys. Acta 1832, 263-274.

Calfon, M., Zeng, H., Urano, F., Till, J.H., Hubbard, S.R., Harding, H.P., Clark, S.G., Ron, D., 2002. IRE1 couples endoplasmic reticulum load to secretory capacity by processing the XBP-1 mRNA. Nature 415, 92-96.

Camins, A., Verdaguer, E., Folch, J., Pallas, M., 2006. Involvement of calpain activation in neurodegenerative processes. CNS Drug Rev. 12, 135-148.

Cartier, A.E., Djakovic, S.N., Salehi, A., Wilson, S.M., Masliah, E., Patrick, G.N., 2009. Regulation of synaptic structure by ubiquitin C-terminal hydrolase L1. J. Neurosci. 29, 7857-7868.

Chen, P.C., Bhattacharyya, B.J., Hanna, J., Minkel, H., Wilson, J.A., Finley, D., Miller, R.J., Wilson, S.M., 2011. Ubiquitin homeostasis is critical for synaptic development and function. J. Neurosci. 31, 17505-17513.

Chen, X., Kintner, D.B., Baba, A., Matsuda, T., Shull, G.E., Sun, D., 2010. Protein aggregation in neurons following OGD: a role for $\mathrm{Na}^{+}$and $\mathrm{Ca}^{2+}$ ionic dysregulation. J. Neurochem. 112, 173-182.

Chernorudskiy, A.L., Gainullin, M.R., 2013. Ubiquitin system: direct effects join the signaling. Sci. Signal. 6, e22.

Choi, A.M., Ryter, S.W., Levine, B., 2013. Autophagy in human health and disease. N. Engl. J. Med. 368, 1845-1846.

Choi, D.W., Maulucci-Gedde, M., Kriegstein, A.R., 1987. Glutamate neurotoxicity in cortical cell culture. J. Neurosci. 7, 357-368.

Chu, J., Hong, N.A., Masuda, C.A., Jenkins, B.V., Nelms, K.A., Goodnow, C.C., Glynne, R.J., Wu, H., Masliah, E., Joazeiro, C.A., Kay, S.A., 2009. A mouse forward genetics screen identifies LISTERIN as an E3 ubiquitin ligase involved in neurodegeneration. Proc. Natl. Acad. Sci. U.S.A. 106, 2097-2103.

Ciechanover, A., 1994. The ubiquitin-proteasome proteolytic pathway. Cell 79 13-21.

Ciechanover, A., Heller, H., Elias, S., Haas, A.L., Hershko, A., 1980. ATP-dependent conjugation of reticulocyte proteins with the polypeptide required for protein degradation. Proc. Natl. Acad. Sci. U.S.A. 77, 1365-1368.

Ciechanover, A., Hod, Y., Hershko, A., 1978. A heat-stable polypeptide component of an ATP-dependent proteolytic system from reticulocytes. Biochem. Biophys. Res. Commun. 81, 1100-1105.

Colledge, M., Snyder, E.M., Crozier, R.A., Soderling, J.A., Jin, Y., Langeberg, L.K., Lu, H. Bear, M.F., Scott, J.D., 2003. Ubiquitination regulates PSD-95 degradation and AMPA receptor surface expression. Neuron 40, 595-607.

Coyle, J.T., Puttfarcken, P., 1993. Oxidative stress, glutamate, and neurodegenerative disorders. Science 262, 689-695.

Crimmins, S., Jin, Y., Wheeler, C., Huffman, A.K., Chapman, C., Dobrunz, L.E., Levey, A., Roth, K.A., Wilson, J.A., Wilson, S.M., 2006. Transgenic rescue of ataxia mice with neuronal-specific expression of ubiquitin-specific protease 14. J. Neurosci. 26, 11423-11431.

Cuervo, A.M., Palmer, A., Rivett, A.J., Knecht, E., 1995. Degradation of proteasomes by lysosomes in rat liver. Eur. J. Biochem. 227, 792-800.

da Fonseca, P.C., He, J., Morris, E.P., 2012. Molecular model of the human $26 \mathrm{~S}$ proteasome. Mol. Cell 46, 54-66.

da Fonseca, P.C., Morris, E.P., 2008. Structure of the human 26S proteasome: subunit radial displacements open the gate into the proteolytic core. J. Biol. Chem. 283, 23305-23314.

Dahlmann, B., Ruppert, T., Kuehn, L., Merforth, S., Kloetzel, P.M., 2000. Different proteasome subtypes in a single tissue exhibit different enzymatic properties. J. Mol. Biol. 303, 643-653.

Dantuma, N.P., Groothuis, T.A., Salomons, F.A., Neefjes, J., 2006. A dynamic ubiquitin equilibrium couples proteasomal activity to chromatin remodeling. J. Cell Biol. $173,19-26$.

Dantuma, N.P., Lindsten, K., Glas, R., Jellne, M., Masucci, M.G., 2000. Short-lived green fluorescent proteins for quantifying ubiquitin/proteasome-dependent proteolysis in living cells. Nat. Biotechnol. 18, 538-543.

de Bie, P., Ciechanover, A., 2011. Ubiquitination of E3 ligases: self-regulation of the ubiquitin system via proteolytic and non-proteolytic mechanisms. Cell Death Differ. 18, 1393-1402. 
DeGracia, D.J., Jamison, J.T., Szymanski, J.J., Lewis, M.K., 2008. Translation arrest and ribonomics in post-ischemic brain: layers and layers of players. J. Neurochem. 106, 2288-2301.

DeGracia, D.J., Montie, H.L., 2004. Cerebral ischemia and the unfolded protein response. J. Neurochem. 91, 1-8.

DeGracia, D.J., Rudolph, J., Roberts, G.G., Rafols, J.A., Wang, J., 2007. Convergence of stress granules and protein aggregates in hippocampal cornu ammonis 1 at later reperfusion following global brain ischemia. Neuroscience 146, 562-572.

Dennissen, F.J., Kholod, N., van Leeuwen, F.W., 2012. The ubiquitin proteasome system in neurodegenerative diseases: culprit, accomplice or victim? Prog. Neurobiol. 96, 190-207.

Deshaies, R.J., Joazeiro, C.A., 2009. RING domain E3 ubiquitin ligases. Annu. Rev. Biochem. 78, 399-434.

Diaz-Hernandez, M., Hernandez, F., Martin-Aparicio, E., Gomez-Ramos, P., Moran, M.A., Castano, J.G., Ferrer, I., Avila, J., Lucas, J.J., 2003. Neuronal induction of the immunoproteasome in Huntington's disease. J. Neurosci. 23, 11653-11661.

Dimova, N.V., Hathaway, N.A., Lee, B.H., Kirkpatrick, D.S., Berkowitz, M.L., Gygi, S.P., Finley, D., King, R.W., 2012. APC/C-mediated multiple monoubiquitylation provides an alternative degradation signal for cyclin B1. Nature Cell Biol. 14, 168-176.

Ding, Q., Dimayuga, E., Markesbery, W.R., Keller, J.N., 2006. Proteasome inhibition induces reversible impairments in protein synthesis. FASEB J. 20, 1055-1063.

Djakovic, S.N., Marquez-Lona, E.M., Jakawich, S.K., Wright, R., Chu, C., Sutton, M.A., Patrick, G.N., 2012. Phosphorylation of Rpt6 regulates synaptic strength in hippocampal neurons. J. Neurosci. 32, 5126-5131.

Djakovic, S.N., Schwarz, L.A., Barylko, B., DeMartino, G.N., Patrick, G.N., 2009 Regulation of the proteasome by neuronal activity and calcium/calmodulindependent protein kinase II. J. Biol. Chem. 284, 26655-26665.

Doeppner, T.R., Doehring, M., Bretschneider, E., Zechariah, A., Kaltwasser, B., Muller, B., Koch, J.C., Bahr, M., Hermann, D.M., Michel, U., 2013. MicroRNA-124 protects against focal cerebral ischemia via mechanisms involving Usp14-dependent REST degradation. Acta Neuropathol. 126, 251-265.

Doeppner, T.R., Mlynarczuk-Bialy, I., Kuckelkorn, U., Kaltwasser, B., Herz, J., Hasan, M.R., Hermann, D.M., Bahr, M., 2012. The novel proteasome inhibitor BSc2118 protects against cerebral ischaemia through HIF1A accumulation and enhanced angioneurogenesis. Brain 135, 3282-3297.

Dong, C., Upadhya, S.C., Ding, L., Smith, T.K., Hegde, A.N., 2008. Proteasome inhibition enhances the induction and impairs the maintenance of late-phase longterm potentiation. Learn. Mem. 15, 335-347.

Doyle, K.P., Simon, R.P., Stenzel-Poore, M.P., 2008. Mechanisms of ischemic brain damage. Neuropharmacology 55, 310-318.

Duttler, S., Pechmann, S., Frydman, J., 2013. Principles of cotranslational ubiquitination and quality control at the ribosome. Mol. Cell 50, 379-393.

Ebert, D.H., Greenberg, M.E., 2013. Activity-dependent neuronal signalling and autism spectrum disorder. Nature 493, 327-337.

Egerer, K., Kuckelkorn, U., Rudolph, P.E., Ruckert, J.C., Dorner, T., Burmester, G.R. Kloetzel, P.M., Feist, E., 2002. Circulating proteasomes are markers of cell damage and immunologic activity in autoimmune diseases. J. Rheumatol. 29 2045-2052.

Ehlers, M.D., 2003. Activity level controls postsynaptic composition and signaling via the ubiquitin-proteasome system. Nat. Neurosci. 6, 231-242.

Elsasser, S., Chandler-Militello, D., Muller, B., Hanna, J., Finley, D., 2004. Rad23 and Rpn10 serve as alternative ubiquitin receptors for the proteasome. J. Biol. Chem. 279, 26817-26822.

Elsasser, S., Gali, R.R., Schwickart, M., Larsen, C.N., Leggett, D.S., Muller, B., Feng, M.T., Tubing, F., Dittmar, G.A.G., Finley, D., 2002. Proteasome subunit Rpn1 binds ubiquitin-like protein domains. Nat. Cell Biol. 4, 725-730.

Erdal, H., Berndtsson, M., Castro, J., Brunk, U., Shoshan, M.C., Linder, S., 2005 Induction of lysosomal membrane permeabilization by compounds that activate p53-independent apoptosis. Proc. Natl. Acad. Sci. U.S.A. 102, 192-197.

Fang, S., Weissman, A.M., 2004. A field guide to ubiquitylation. Cell Mol. Life Sci. 61, 1546-1561.

Farooqui, A.A., Horrocks, L.A., 1994. Involvement of glutamate receptors, lipases, and phospholipases in long-term potentiation and neurodegeneration. J. Neurosci. Res. 38, 6-11.

Fedorova, O.A., Moiseeva, T.N., Nikiforov, A.A., Tsimokha, A.S., Livinskaya, V.A. Hodson, M., Bottrill, A., Evteeva, I.N., Ermolayeva, J.B., Kuznetzova, I.M., Turoverov, K.K., Eperon, I., Barlev, N.A., 2011. Proteomic analysis of the 20S proteasome (PSMA3)-interacting proteins reveals a functional link between the proteasome and mRNA metabolism. Biochem. Biophys. Res. Commun. 416, 258-265.

Feng, P., Ma, Y., Vogel, G.W., 2001. The critical window of brain development from susceptive to insusceptive. Effects of clomipramine neonatal treatment on sexual behavior. Brain Res. Dev. Brain Res. 129, 107-110.

Ferreira, I.L., Duarte, C.B., Carvalho, A.P., 1996. $\mathrm{Ca}^{2+}$ influx through glutamate receptor-associated channels in retina cells correlates with neuronal cell death. Eur. J. Pharmacol. 302, 153-162.

Ferreira, I.L., Duarte, C.B., Carvalho, A.P., 1998. Kainate-induced retina amacrine-like cell damage is mediated by AMPA receptors. Neuroreport 9, 3471-3475.

Finley, D., Ulrich, H.D., Sommer, T., Kaiser, P., 2012. The ubiquitin-proteasome system of Saccharomyces cerevisiae. Genetics 192, 319-360.

Ge, P., Luo, Y., Liu, C.L., Hu, B., 2007. Protein aggregation and proteasome dysfunction after brain ischemia. Stroke 38, 3230-3236.

Ge, P., Zhang, F., Zhao, J., Liu, C., Sun, L., Hu, B., 2012. Protein degradation pathways after brain ischemia. Curr. Drug Targets 13, 159-165.
Glickman, M.H., Ciechanover, A., 2002. The ubiquitin-proteasome proteolytic pathway: destruction for the sake of construction. Physiol. Rev. 82, 373-428.

Goldberg, A.L., Cascio, P., Saric, T., Rock, K.L., 2002. The importance of the proteasome and subsequent proteolytic steps in the generation of antigenic peptides. Mol. Immunol. 39, 147-164

Goldberg, M.P., Choi, D.W., 1993. Combined oxygen and glucose deprivation in cortical cell culture: calcium-dependent and calcium-independent mechanisms of neuronal injury. J. Neurosci. 13, 3510-3524.

Goldstein, G., 1974. Isolation of bovine thymin: a polypeptide hormone of the thymus. Nature 247, 11-14

Goldstein, G., Scheid, M., Hammerling, U., Schlesinger, D.H., Niall, H.D., Boyse, E.A., 1975. Isolation of a polypeptide that has lymphocyte-differentiating properties and is probably represented universally in living cells. Proc. Natl. Acad. Sci. U.S.A. 72, 11-15.

Gomes, J.R., Costa, J.T., Melo, C.V., Felizzi, F., Monteiro, P., Pinto, M.J., Inacio, A.R., Wieloch, T., Almeida, R.D., Graos, M., Duarte, C.B., 2012. Excitotoxicity downregulates TrkB.FL signaling and upregulates the neuroprotective truncated TrkB receptors in cultured hippocampal and striatal neurons. J. Neurosci. 32, 46104622 .

Gomes, J.R., Lobo, A.C., Melo, C.V., Inacio, A.R., Takano, J., Iwata, N., Saido, T.C., de Almeida, L.P., Wieloch, T., Duarte, C.B., 2011. Cleavage of the vesicular GABA transporter under excitotoxic conditions is followed by accumulation of the truncated transporter in nonsynaptic sites. J. Neurosci. 31, 4622-4635.

Gould, E., Cameron, H.A., McEwen, B.S., 1994. Blockade of NMDA receptors increases cell death and birth in the developing rat dentate gyrus. J. Comp. Neurol. 340, 551-565.

Grabbe, C., Husnjak, K., Dikic, I., 2011. The spatial and temporal organization of ubiquitin networks. Nature reviews. Mol. Cell. Biol. 12, 295-307.

Greer, P.L., Hanayama, R., Bloodgood, B.L., Mardinly, A.R., Lipton, D.M., Flavell, S.W., Kim, T.K., Griffith, E.C., Waldon, Z., Maehr, R., Ploegh, H.L., Chowdhury, S. Worley, P.F., Steen, J., Greenberg, M.E., 2010. The Angelman Syndrome protein Ube3A regulates synapse development by ubiquitinating arc. Cell 140, 704716 .

Grewer, C., Gameiro, A., Zhang, Z., Tao, Z., Braams, S., Rauen, T., 2008. Glutamate forward and reverse transport: from molecular mechanism to transportermediated release after ischemia. IUBMB Life 60, 609-619.

Groll, M., Ditzel, L., Lowe, J., Stock, D., Bochtler, M., Bartunik, H.D., Huber, R., 1997. Structure of 20 S proteasome from yeast at $2.4 \AA$ resolution. Nature 386,463 471

Groothuis, T.A., Dantuma, N.P., Neefjes, J., Salomons, F.A., 2006. Ubiquitin crosstalk connecting cellular processes. Cell Div. 1, 21.

Gu, L., Liu, X., Yang, Y., Luo, D., Zheng, X., 2010. ASICs aggravate acidosis-induced injuries during ischemic reperfusion. Neurosci. Lett. 479, 63-68.

Guerrero, C., Tagwerker, C., Kaiser, P., Huang, L., 2006. An integrated mass spectrometry-based proteomic approach: quantitative analysis of tandem affinitypurified in vivo cross-linked protein complexes (QTAX) to decipher the $26 \mathrm{~S}$ proteasome-interacting network. Mol. Cell. Proteomics 5, 366-378.

Guterman, A., Glickman, M.H., 2004. Complementary roles for Rpn11 and Ubp6 in deubiquitination and proteolysis by the proteasome. J. Biol. Chem. 279, 17291738.

Hamilton, A.M., Oh, W.C., Vega-Ramirez, H., Stein, I.S., Hell, J.W., Patrick, G.N., Zito, K., 2012. Activity-dependent growth of new dendritic spines is regulated by the proteasome. Neuron 74, 1023-1030.

Hamilton, A.M., Zito, K., 2013. Breaking it down: the ubiquitin proteasome system in neuronal morphogenesis. Neural Plast. 2013, 196848.

Hansen, A.J., 1985. Effect of anoxia on ion distribution in the brain. Physiol. Rev. 65, $101-148$.

Hara, T., Nakamura, K., Matsui, M., Yamamoto, A., Nakahara, Y., Suzuki-Migishima, R., Yokoyama, M., Mishima, K., Saito, I., Okano, H., Mizushima, N., 2006. Suppression of basal autophagy in neural cells causes neurodegenerative disease in mice. Nature 441, 885-889

Harding, H.P., Novoa, I., Zhang, Y., Zeng, H., Wek, R., Schapira, M., Ron, D., 2000 Regulated translation initiation controls stress-induced gene expression in mammalian cells. Mol. Cell 6, 1099-1108.

Hardingham, G.E., Bading, H., 2003. The Yin and Yang of NMDA receptor signalling. Trends Neurosci. 26, 81-89.

Hardingham, G.E., Fukunaga, Y., Bading, H., 2002. Extrasynaptic NMDARs oppose synaptic NMDARs by triggering CREB shut-off and cell death pathways. Nat. Neurosci. 5, 405-414.

Harvey, B.K., Airavaara, M., Hinzman, J., Wires, E.M., Chiocco, M.J., Howard, D.B., Shen, H., Gerhardt, G., Hoffer, B.J., Wang, Y., 2011. Targeted over-expression of glutamate transporter 1 (GLT-1) reduces ischemic brain injury in a rat model of stroke. PLoS One 6, e22135.

Hayashi, T., Saito, A., Okuno, S., Ferrand-Drake, M., Dodd, R.L., Chan, P.H., 2004. Oxidative injury to the endoplasmic reticulum in mouse brains after transient focal ischemia. Neurobiol. Dis. 15, 229-239.

Hayashi, T., Saito, A., Okuno, S., Ferrand-Drake, M., Dodd, R.L., Nishi, T., Maier, C.M., Kinouchi, H., Chan, P.H., 2003. Oxidative damage to the endoplasmic reticulum is implicated in ischemic neuronal cell death. J. Cereb. Blood Flow Metab. 23, 1117-1128.

Hayashi, T., Takada, K., Matsuda, M., 1992. Post-transient ischemia increase in ubiquitin conjugates in the early reperfusion. Neuroreport 3, 519-520.

Heales, S.J., Bolanos, J.P., Stewart, V.C., Brookes, P.S., Land, J.M., Clark, J.B., 1999 Nitric oxide, mitochondria and neurological disease. Biochim. Biophys. Acta 1410, 215-228. 
Hershko, A., Ciechanover, A., 1998. The ubiquitin system. Annu. Rev. Biochem. 67, 425-479.

Hershko, A., Heller, H., Elias, S., Ciechanover, A., 1983. Components of ubiquitinprotein ligase system. Resolution, affinity purification, and role in protein breakdown. J. Biol. Chem. 258, 8206-8214.

Hertz, L., 2008. Bioenergetics of cerebral ischemia: a cellular perspective. Neuropharmacology 55, 289-309.

Hochrainer, K., Jackman, K., Anrather, J., Iadecola, C., 2012. Reperfusion rather than ischemia drives the formation of ubiquitin aggregates after middle cerebral artery occlusion. Stroke 43, 2229-2235.

Hofmeijer, J., van Putten, M.J., 2012. Ischemic cerebral damage: an appraisal of synaptic failure. Stroke 43, 607-615.

Hoppe, T., 2005. Multiubiquitylation by E4 enzymes: 'one size' doesn't fit all. Trends Biochem. Sci. 30, 183-187.

Hou, Q., Gilbert, J., Man, H.Y., 2011. Homeostatic regulation of AMPA receptor trafficking and degradation by light-controlled single-synaptic activation. Neuron $72,806-818$.

Hu, B.R., Janelidze, S., Ginsberg, M.D., Busto, R., Perez-Pinzon, M., Sick, T.J., Siesjo, B.K., Liu, C.L., 2001. Protein aggregation after focal brain ischemia and reperfusion. J. Cereb. Blood Flow Metab. 21, 865-875.

Hu, B.R., Martone, M.E., Jones, Y.Z., Liu, C.L., 2000. Protein aggregation after transient cerebral ischemia. J. Neurosci. 20, 3191-3199.

Huang, Q., Wang, H., Perry, S.W., Figueiredo-Pereira, M.E., 2013. Negative regulation of $26 \mathrm{~S}$ proteasome stability via calpain-mediated cleavage of Rpn10 subunit upon mitochondrial dysfunction in neurons. J. Biol. Chem. 288, 12161-12174.

Hung, A.Y., Sung, C.C., Brito, I.L., Sheng, M., 2010. Degradation of postsynaptic scaffold GKAP and regulation of dendritic spine morphology by the TRIM3 ubiquitin ligase in rat hippocampal neurons. PLoS One 5, e9842.

Husnjak, K., Elsasser, S., Zhang, N., Chen, X., Randles, L., Shi, Y., Hofmann, K., Walters, K.J., Finley, D., Dikic, I., 2008. Proteasome subunit Rpn13 is a novel ubiquitin receptor. Nature 453, 481-488.

Ide, T., Takada, K., Qiu, J.H., Saito, N., Kawahara, N., Asai, A., Kirino, T., 1999. Ubiquitin stress response in postischemic hippocampal neurons under nontolerant and tolerant conditions. J. Cereb. Blood Flow Metab. 19, 750-756.

Jia, J., Verma, S., Nakayama, S., Quillinan, N., Grafe, M.R., Hurn, P.D., Herson, P.S., 2011. Sex differences in neuroprotection provided by inhibition of TRPM2 channels following experimental stroke. J. Cereb. Blood Flow Metab. 31, 2160-2168.

Jiang, X., Litkowski, P.E., Taylor, A.A., Lin, Y., Snider, B.J., Moulder, K.L., 2010. A role for the ubiquitin-proteasome system in activity-dependent presynaptic silencing. J. Neurosci. 30, 1798-1809.

Jin, J., Li, X., Gygi, S.P., Harper, J.W., 2007. Dual E1 activation systems for ubiquitin differentially regulate E2 enzyme charging. Nature 447, 1135-1138.

Jurd, R., Thornton, C., Wang, J., Luong, K., Phamluong, K., Kharazia, V., Gibb, S.L., Ron, D., 2008. Mind bomb-2 is an E3 ligase that ubiquitinates the N-methyl-Daspartate receptor NR2B subunit in a phosphorylation-dependent manner. J. Biol. Chem. 283, 301-310.

Kamikubo, T., Hayashi, T., 1996. Changes in proteasome activity following transient ischemia. Neurochem. Int. 28, 209-212.

Karpova, A., Mikhaylova, M., Bera, S., Bar, J., Reddy, P.P., Behnisch, T., Rankovic, V., Spilker, C., Bethge, P., Sahin, J., Kaushik, R., Zuschratter, W., Kahne, T., Naumann, M., Gundelfinger, E.D., Kreutz, M.R., 2013. Encoding and transducing the synaptic or extrasynaptic origin of NMDA receptor signals to the nucleus. Cell 152, 1119-1133.

Kato, A., Rouach, N., Nicoll, R.A., Bredt, D.S., 2005. Activity-dependent NMDA receptor degradation mediated by retrotranslocation and ubiquitination. Proc. Natl. Acad. Sci. U.S.A. 102, 5600-5605.

Kaufman, A.M., Milnerwood, A.J., Sepers, M.D., Coquinco, A., She, K., Wang, L., Lee, H., Craig, A.M., Cynader, M., Raymond, L.A., 2012. Opposing roles of synaptic and extrasynaptic NMDA receptor signaling in cocultured striatal and cortical neurons. J. Neurosci. 32, 3992-4003.

Keller, J.N., Huang, F.F., Zhu, H., Yu, J., Ho, Y.S., Kindy, T.S., 2000. Oxidative stressassociated impairment of proteasome activity during ischemia-reperfusion injury. J. Cereb. Blood Flow Metab. 20, 1467-1473.

Keller, J.N., Markesbery, W.R., 2000. Proteasome inhibition results in increased polyADP-ribosylation: implications for neuron death. J. Neurosci. Res. 61, 436-442.

Kim, W., Bennett, E.J., Huttlin, E.L., Guo, A., Li, J., Possemato, A., Sowa, M.E., Rad, R., Rush, J., Comb, M.J., Harper, J.W., Gygi, S.P., 2011. Systematic and quantitative assessment of the ubiquitin-modified proteome. Mol. Cell 44, 325-340.

Kimelberg, H.K., Mongin, A.A., 1998. Swelling-activated release of excitatory amino acids in the brain: relevance for pathophysiology. Contrib. Nephrol. 123, 240257.

Kirino, T., 1982. Delayed neuronal death in the gerbil hippocampus following ischemia. Brain Res. 239, 57-69.

Koegl, M., Hoppe, T., Schlenker, S., Ulrich, H.D., Mayer, T.U., Jentsch, S., 1999. A novel ubiquitination factor, E4, is involved in multiubiquitin chain assembly. Cell 96 635-644.

Kohler, A., Cascio, P., Leggett, D.S., Woo, K.M., Goldberg, A.L., Finley, D., 2001. The axial channel of the proteasome core particle is gated by the Rpt2 ATPase and controls both substrate entry and product release. Mol. Cell 7, 1143-1152.

Kohno, K., Higuchi, T., Ohta, S., Kumon, Y., Sakaki, S., 1997. Neuroprotective nitric oxide synthase inhibitor reduces intracellular calcium accumulation following transient global ischemia in the gerbil. Neurosci. Lett. 224, 17-20.

Kokame, K., Agarwala, K.L., Kato, H., Miyata, T., 2000. Herp, a new ubiquitin-like membrane protein induced by endoplasmic reticulum stress. J. Biol. Chem. 275, 32846-32853.
Kokame, K., Kato, H., Miyata, T., 2001. Identification of ERSE-II, a new cis-acting element responsible for the ATF6-dependent mammalian unfolded protein response. J. Biol. Chem. 276, 9199-9205.

Komander, D., Clague, M.J., Urbe, S., 2009. Breaking the chains: structure and function of the deubiquitinases. Nature reviews. Mol. Cell. Biol. 10, 550-563.

Komatsu, M., Waguri, S., Chiba, T., Murata, S., Iwata, J., Tanida, I., Ueno, T., Koike, M. Uchiyama, Y., Kominami, E., Tanaka, K., 2006. Loss of autophagy in the central nervous system causes neurodegeneration in mice. Nature 441, 880-884.

Korb, E., Wilkinson, C.L., Delgado, R.N., Lovero, K.L., Finkbeiner, S., 2013. Arc in the nucleus regulates PML-dependent GluA1 transcription and homeostatic plasticity. Nat. Neurosci. 16, 874-883.

Kostandy, B.B., 2012. The role of glutamate in neuronal ischemic injury: the role of spark in fire. Neurol. Sci. 33, 223-237.

Koulich, E., Li, X., DeMartino, G.N., 2008. Relative structural and functional roles of multiple deubiquitylating proteins associated with mammalian 265 proteasome. Mol. Biol. Cell 19, 1072-1082.

Kulathu, Y., Komander, D., 2012. Atypical ubiquitylation-the unexplored world of polyubiquitin beyond Lys48 and Lys63 linkages. Nat. Rev. Mol. Cell. Biol. 13, 508-523.

Kumar, R., Azam, S., Sullivan, J.M., Owen, C., Cavener, D.R., Zhang, P., Ron, D., Harding, H.P., Chen, J.J., Han, A., White, B.C., Krause, G.S., DeGracia, D.J., 2001. Brain ischemia and reperfusion activates the eukaryotic initiation factor 2alpha kinase, PERK. J. Neurochem. 77, 1418-1421.

Kumar, R., Krause, G.S., Yoshida, H., Mori, K., DeGracia, D.J., 2003. Dysfunction of the unfolded protein response during global brain ischemia and reperfusion. J. Cereb. Blood Flow Metab. 23, 462-471.

Lam, Y.A., Lawson, T.G., Velayutham, M., Zweier, J.L., Pickart, C.M., 2002. A proteasomal ATPase subunit recognizes the polyubiquitin degradation signal. Nature 416, 763-767.

Lamark, T., Kirkin, V., Dikic, I., Johansen, T., 2009. NBR1 and p62 as cargo receptors for selective autophagy of ubiquitinated targets. Cell Cycle 8, 1986-1990.

Lander, G.C., Estrin, E., Matyskiela, M.E., Bashore, C., Nogales, E., Martin, A., 2012 Complete subunit architecture of the proteasome regulatory particle. Nature 482, 186-191.

Lavabre-Bertrand, T., Henry, L., Carillo, S., Guiraud, I., Ouali, A., Dutaud, D., Aubry, L., Rossi, J.F., Bureau, J.P., 2001. Plasma proteasome level is a potential marker in patients with solid tumors and hemopoietic malignancies. Cancer 92, 2493 2500.

Lee, B.H., Lee, M.J., Park, S., Oh, D.C., Elsasser, S., Chen, P.C., Gartner, C., Dimova, N., Hanna, J., Gygi, S.P., Wilson, S.M., King, R.W., Finley, D., 2010. Enhancement of proteasome activity by a small-molecule inhibitor of USP14. Nature 467, 179 184.

Lee, J.M., Zipfel, G.J., Choi, D.W., 1999. The changing landscape of ischaemic brain injury mechanisms. Nature 399, A7-A14.

Lee, P.C., Dodart, J.C., Aron, L., Finley, L.W., Bronson, R.T., Haigis, M.C., Yankner, B.A., Harper, J.W., 2013. Altered social behavior and neuronal development in mice lacking the Uba6-Use1 ubiquitin transfer system. Mol. Cell 50, 172-184.

Leggett, D.S., Hanna, J., Borodovsky, A., Crosas, B., Schmidt, M., Baker, R.T., Walz, T. Ploegh, H., Finley, D., 2002. Multiple associated proteins regulate proteasome structure and function. Mol. Cell 10, 495-507.

Leveille, F., Papadia, S., Fricker, M., Bell, K.F., Soriano, F.X., Martel, M.A., Puddifoot, C. Habel, M., Wyllie, D.J., Ikonomidou, C., Tolkovsky, A.M., Hardingham, G.E., 2010. Suppression of the intrinsic apoptosis pathway by synaptic activity. J. Neurosci. 30, 2623-2635.

Li, Z.Y., Liu, B., Yu, J., Yang, F.W., Luo, Y.N., Ge, P.F., 2012. Ischaemic postconditioning rescues brain injury caused by focal ischaemia/reperfusion via attenuation of protein oxidization. J. Int. Med. Res. 40, 954-966.

Liang, J., Yao, J., Wang, G., Wang, Y., Wang, B., Ge, P., 2012. Ischemic postconditioning protects neuronal death caused by cerebral ischemia and reperfusion via attenuating protein aggregation. Int. J. Med. Sci. 9, 923-932.

Lin, A., Hou, Q., Jarzylo, L., Amato, S., Gilbert, J., Shang, F., Man, H.Y., 2011. Nedd4mediated AMPA receptor ubiquitination regulates receptor turnover and trafficking. J. Neurochem. 119, 27-39.

Lindsten, K., de Vrij, F.M., Verhoef, L.G., Fischer, D.F., van Leeuwen, F.W., Hol, E.M. Masucci, M.G., Dantuma, N.P., 2002. Mutant ubiquitin found in neurodegenerative disorders is a ubiquitin fusion degradation substrate that blocks proteasomal degradation. J. Cell Biol. 157, 417-427.

Lipski, J., Park, T.I., Li, D., Lee, S.C., Trevarton, A.J., Chung, K.K., Freestone, P.S., Bai, J.Z. 2006. Involvement of TRP-like channels in the acute ischemic response of hippocampal CA1 neurons in brain slices. Brain Res. 1077, 187-199.

Lipton, P., 1999. Ischemic cell death in brain neurons. Physiol. Rev. 79, 1431-1568.

Liu, B., Liao, M., Mielke, J.G., Ning, K., Chen, Y., Li, L., El-Hayek, Y.H., Gomez, E. Zukin, R.S., Fehlings, M.G., Wan, Q., 2006. Ischemic insults direct glutamate receptor subunit 2-lacking AMPA receptors to synaptic sites. J. Neurosci. 26 5309-5319.

Liu, C., Gao, Y., Barrett, J., Hu, B., 2010. Autophagy and protein aggregation after brain ischemia. J. Neurochem. 115, 68-78.

Liu, C.L., Ge, P., Zhang, F., Hu, B.R., 2005. Co-translational protein aggregation after transient cerebral ischemia. Neuroscience 134, 1273-1284.

Liu, C.L., Martone, M.E., Hu, B.R., 2004. Protein ubiquitination in postsynaptic densities after transient cerebral ischemia. J. Cereb. Blood Flow Metab. 24 1219-1225.

Liu, C.W., Jacobson, A.D., 2013. Functions of the $19 \mathrm{~S}$ complex in proteasomal degradation. Trends Biochem. Sci. 38, 103-110.

Liu, H., Li, W., Ahmad, M., Rose, M.E., Miller, T.M., Yu, M., Chen, J., Pascoe, J.L., Poloyac, S.M., Hickey, R.W., Graham, S.H., 2013. Increased generation of cyclopentenone 
prostaglandins after brain ischemia and their role in aggregation of ubiquitinated proteins in neurons. Neurotoxicol. Res. 24, 191-204.

Lobo, A.C., Gomes, J.R., Catarino, T., Mele, M., Fernandez, P., Inacio, A.R., Bahr, B.A., Santos, A.E., Wieloch, T., Carvalho, A.L., Duarte, C.B., 2011. Cleavage of the vesicular glutamate transporters under excitotoxic conditions. Neurobiol. Dis. 44, 292-303.

Loukissa, A., Cardozo, C., Altschuller-Felberg, C., Nelson, J.E., 2000. Control of LMP7 expression in human endothelial cells by cytokines regulating cellular and humoral immunity. Cytokine 12, 1326-1330.

Love, K.R., Catic, A., Schlieker, C., Ploegh, H.L., 2007. Mechanisms, biology and inhibitors of deubiquitinating enzymes. Nat. Chem. Biol. 3, 697-705.

Lu, L., Wang, H., 2012. Transient focal cerebral ischemia upregulates immunoproteasomal subunits. Cell. Mol. Neurobiol. 32, 965-970.

Lu, X., Rong, Y., Bi, R., Baudry, M., 2000. Calpain-mediated truncation of rat brain AMPA receptors increases their Triton X-100 solubility. Brain Res. 863, $143-$ 150.

Lussier, M.P., Herring, B.E., Nasu-Nishimura, Y., Neutzner, A., Karbowski, M., Youle, R.J., Nicoll, R.A., Roche, K.W., 2012. Ubiquitin ligase RNF167 regulates AMPA receptor-mediated synaptic transmission. Proc. Natl. Acad. Sci. U.S.A. 109, 19426-19431.

Lussier, M.P., Nasu-Nishimura, Y., Roche, K.W., 2011. Activity-dependent ubiquitination of the AMPA receptor subunit GluA2. J. Neurosci. 31, 3077-3081.

Ma, Y., Brewer, J.W., Diehl, J.A., Hendershot, L.M., 2002. Two distinct stress signaling pathways converge upon the CHOP promoter during the mammalian unfolded protein response. J. Mol. Biol. 318, 1351-1365.

Maestre, C., Delgado-Esteban, M., Gomez-Sanchez, J.C., Bolanos, J.P., Almeida, A., 2008. Cdk5 phosphorylates Cdh1 and modulates cyclin B1 stability in excitotoxicity. EMBO J. 27, 2736-2745.

Magnusson, K., Wieloch, T., 1989. Impairment of protein ubiquitination may cause delayed neuronal death. Neurosci. Lett. 96, 264-270.

Manev, H., Favaron, M., Guidotti, A., Costa, E., 1989. Delayed increase of $\mathrm{Ca}^{2+}$ influx elicited by glutamate: role in neuronal death. Mol. Pharmacol. 36, 106-112.

Martel, M.A., Ryan, T.J., Bell, K.F., Fowler, J.H., McMahon, A., Al-Mubarak, B. Komiyama, N.H., Horsburgh, K., Kind, P.C., Grant, S.G., Wyllie, D.J., Hardingham, G.E., 2012. The subtype of GluN2 C-terminal domain determines the response to excitotoxic insults. Neuron 74, 543-556.

Martinez-Sanchez, M., Striggow, F., Schroder, U.H., Kahlert, S., Reymann, K.G., Reiser G., 2004. $\mathrm{Na}^{+}$and $\mathrm{Ca}^{2+}$ homeostasis pathways, cell death and protection after oxygen-glucose-deprivation in organotypic hippocampal slice cultures. Neuroscience $128,729-740$

Meller, R., 2009. The role of the ubiquitin proteasome system in ischemia and ischemic tolerance. Neuroscientist 15, 243-260.

Meller, R., Cameron, J.A., Torrey, D.J., Clayton, C.E., Ordonez, A.N., Henshall, D.C. Minami, M., Schindler, C.K., Saugstad, J.A., Simon, R.P., 2006. Rapid degradation of Bim by the ubiquitin-proteasome pathway mediates short-term ischemic tolerance in cultured neurons. J. Biol. Chem. 281, 7429-7436.

Meller, R., Thompson, S.J., Lusardi, T.A., Ordonez, A.N., Ashley, M.D., Jessick, V. Wang, W., Torrey, D.J., Henshall, D.C., Gafken, P.R., Saugstad, J.A., Xiong, Z.G., Simon, R.P., 2008. Ubiquitin proteasome-mediated synaptic reorganization: novel mechanism underlying rapid ischemic tolerance. J. Neurosci. 28, 50-59.

Melo, C.V., Okumoto, S., Gomes, J.R., Baptista, M.S., Bahr, B.A., Frommer, W.B. Duarte, C.B., 2013. Spatiotemporal resolution of BDNF neuroprotection against glutamate excitotoxicity in cultured hippocampal neurons. Neuroscience 237 66-86.

Miao, S., Chen, R., Ye, J., Tan, G.H., Li, S., Zhang, J., Jiang, Y.H., Xiong, Z.Q., 2013. The Angelman syndrome protein Ube3a is required for polarized dendrite morphogenesis in pyramidal neurons. J. Neurosci. 33, 327-333.

Mies, G., Paschen, W., Hossmann, K.A., 1990. Cerebral blood flow, glucose utilization, regional glucose, and ATP content during the maturation period of delayed ischemic injury in gerbil brain. J. Cereb. Blood Flow Metab. 10, 638-645.

Mishto, M., Bellavista, E., Ligorio, C., Textoris-Taube, K., Santoro, A., Giordano, M. D’Alfonso, S., Listi, F., Nacmias, B., Cellini, E., Leone, M., Grimaldi, L.M., Fenoglio, C., Esposito, F., Martinelli-Boneschi, F., Galimberti, D., Scarpini, E., Seifert, U., Amato, M.P., Caruso, C., Foschini, M.P., Kloetzel, P.M., Franceschi, C., 2010 Immunoproteasome LMP2 $60 \mathrm{HH}$ variant alters MBP epitope generation and reduces the risk to develop multiple sclerosis in Italian female population. PLoS One 5, e9287.

Mishto, M., Bellavista, E., Santoro, A., Stolzing, A., Ligorio, C., Nacmias, B., Spazzafumo, L., Chiappelli, M., Licastro, F., Sorbi, S., Pession, A., Ohm, T., Grune, T. Franceschi, C., 2006. Immunoproteasome and LMP2 polymorphism in aged and Alzheimer's disease brains. Neurobiol. Aging 27, 54-66.

Monnerie, H., Hsu, F.C., Coulter, D.A., Le Roux, P.D., 2010. Role of the NR2A/2B subunits of the $\mathrm{N}$-methyl-D-aspartate receptor in glutamate-induced glutamic acid decarboxylase alteration in cortical GABAergic neurons in vitro. Neuroscience $171,1075-1090$.

Morimoto, T., Ide, T., Ihara, Y., Tamura, A., Kirino, T., 1996. Transient ischemia depletes free ubiquitin in the gerbil hippocampal CA1 neurons. Am. J. Pathol. $148,249-257$.

Moskowitz, M.A., Lo, E.H., Iadecola, C., 2010. The science of stroke: mechanisms in search of treatments. Neuron 67, 181-198.

Mouw, G., Zechel, J.L., Gamboa, J., Lust, W.D., Selman, W.R., Ratcheson, R.A., 2003. Activation of caspase-12, an endoplasmic reticulum resident caspase, after permanent focal ischemia in rat. Neuroreport 14, 183-186.

Myeku, N., Figueiredo-Pereira, M.E., 2011. Dynamics of the degradation of ubiquitinated proteins by proteasomes and autophagy: association with sequestosome 1/p62. J. Biol. Chem. 286, 22426-22440.
Na, C.H., Jones, D.R., Yang, Y., Wang, X., Xu, Y., Peng, J., 2012. Synaptic protein ubiquitination in rat brain revealed by antibody-based ubiquitome analysis. J. Proteome Res. 11, 4722-4732.

Nakagawa, T., Zhu, H., Morishima, N., Li, E., Xu, J., Yankner, B.A., Yuan, J., 2000. Caspase-12 mediates endoplasmic-reticulum-specific apoptosis and cytotoxicity by amyloid-beta. Nature 403, 98-103.

Nakka, V.P., Gusain, A., Raghubir, R., 2010. Endoplasmic reticulum stress plays critical role in brain damage after cerebral ischemia/reperfusion in rats. Neurotoxicol. Res. 17, 189-202.

Nathan, J.A., Kim, H.T., Ting, L., Gygi, S.P., Goldberg, A.L., 2013. Why do cellular proteins linked to K63-polyubiquitin chains not associate with proteasomes? EMBO J. 32, 552-565

Neumar, R.W., Meng, F.H., Mills, A.M., Xu, Y.A., Zhang, C., Welsh, F.A., Siman, R., 2001 Calpain activity in the rat brain after transient forebrain ischemia. Exp. Neurol. 170, 27-35.

Noh, K.M., Yokota, H., Mashiko, T., Castillo, P.E., Zukin, R.S., Bennett, M.V., 2005 Blockade of calcium-permeable AMPA receptors protects hippocampal neurons against global ischemia-induced death. Proc. Natl. Acad. Sci. U.S.A. 102, 12230 12235

Ogiso, Y., Tomida, A., Tsuruo, T., 2002. Nuclear localization of proteasomes participates in stress-inducible resistance of solid tumor cells to topoisomerase IIdirected drugs. Cancer Res. 62, 5008-5012.

Olney, J.W., 1969. Brain lesions, obesity, and other disturbances in mice treated with monosodium glutamate. Science 164, 719-721.

Osada, N., Kosuge, Y., Ishige, K., Ito, Y., 2010. Characterization of neuronal and astroglial responses to ER stress in the hippocampal CA1 area in mice following transient forebrain ischemia. Neurochem. Int. 57, 1-7.

Ouyang, Y.B., Xu, L., Giffard, R.G., 2005. Geldanamycin treatment reduces delayed CA1 damage in mouse hippocampal organotypic cultures subjected to oxygen glucose deprivation. Neurosci. Lett. 380, 229-233.

Papadia, S., Soriano, F.X., Leveille, F., Martel, M.A., Dakin, K.A., Hansen, H.H., Kaindl, A., Sifringer, M., Fowler, J., Stefovska, V., McKenzie, G., Craigon, M., Corriveau, R., Ghazal, P., Horsburgh, K., Yankner, B.A., Wyllie, D.J., Ikonomidou, C., Hardingham, G.E., 2008. Synaptic NMDA receptor activity boosts intrinsic antioxidant defenses. Nat. Neurosci. 11, 476-487.

Papouin, T., Ladepeche, L., Ruel, J., Sacchi, S., Labasque, M., Hanini, M., Groc, L., Pollegioni, L., Mothet, J.P., Oliet, S.H., 2012. Synaptic and extrasynaptic NMDA receptors are gated by different endogenous coagonists. Cell 150, 633-646.

Park, H.K., Chu, K., Jung, K.H., Lee, S.T., Bahn, J.J., Kim, M., Lee, S.K., Roh, J.K., 2009. Autophagy is involved in the ischemic preconditioning. Neurosci. Lett. 451, 1619.

Parsons, J.T., Churn, S.B., DeLorenzo, R.J., 1997. Ischemia-induced inhibition of calcium uptake into rat brain microsomes mediated by $\mathrm{Mg}^{2+} / \mathrm{Ca}^{2+}$ ATPase. J. Neurochem. 68, 1124-1134.

Parsons, J.T., Churn, S.B., DeLorenzo, R.J., 1999. Global ischemia-induced inhibition of the coupling ratio of calcium uptake and ATP hydrolysis by rat whole brain microsomal $\mathrm{Mg}^{2+} / \mathrm{Ca}^{2+}$ ATPase. Brain Res. 834, 32-41.

Paschen, W., Aufenberg, C., Hotop, S., Mengesdorf, T., 2003. Transient cerebral ischemia activates processing of xbp1 messenger RNA indicative of endoplasmic reticulum stress. J. Cereb. Blood Flow Metab. 23, 449-461.

Paschen, W., Gissel, C., Linden, T., Althausen, S., Doutheil, J., 1998. Activation of gadd153 expression through transient cerebral ischemia: evidence that ischemia causes endoplasmic reticulum dysfunction. Brain Res. Mol. Brain Res. 60, 115-122.

Paschen, W., Mengesdorf, T., 2005. Endoplasmic reticulum stress response and neurodegeneration. Cell Calcium 38, 409-415.

Patrick, G.N., Bingol, B., Weld, H.A., Schuman, E.M., 2003. Ubiquitin-mediated proteasome activity is required for agonist-induced endocytosis of GluRs. Curr. Biol. 13, 2073-2081.

Pavlopoulos, E., Trifilieff, P., Chevaleyre, V., Fioriti, L., Zairis, S., Pagano, A., Malleret, G., Kandel, E.R., 2011. Neuralized1 activates CPEB3: a function for nonproteolytic ubiquitin in synaptic plasticity and memory storage. Cell 147, 1369-1383.

Peters, J.M., 2002. The anaphase-promoting complex: proteolysis in mitosis and beyond. Mol. Cell 9, 931-943.

Peth, A., Besche, H.C., Goldberg, A.L., 2009. Ubiquitinated proteins activate the proteasome by binding to Usp14/Ubp6, which causes 20S gate opening. Mol. Cell 36, 794-804.

Peth, A., Kukushkin, N., Bosse, M., Goldberg, A.L., 2013. Ubiquitinated proteins activate the proteasomal ATPases by binding to Usp14 or Uch37 homologs. J. Biol. Chem. 288, 7781-7790.

Petito, C.K., Pulsinelli, W.A., 1984. Delayed neuronal recovery and neuronal death in rat hippocampus following severe cerebral ischemia: possible relationship to abnormalities in neuronal processes. J. Cereb. Blood Flow Metab. 4, 194-205.

Phillips, J.B., Williams, A.J., Adams, J., Elliott, P.J., Tortella, F.C., 2000. Proteasome inhibitor PS519 reduces infarction and attenuates leukocyte infiltration in a rat model of focal cerebral ischemia. Stroke 31, 1686-1693.

Pickart, C.M., 2004. Back to the future with ubiquitin. Cell 116, 181-190.

Pottorf 2nd, W.J., Johanns, T.M., Derrington, S.M., Strehler, E.E., Enyedi, A., Thayer, S.A., 2006. Glutamate-induced protease-mediated loss of plasma membrane Ca2+ pump activity in rat hippocampal neurons. J. Neurochem. 98, 1646-1656.

Pulsinelli, W.A., Brierley, J.B., Plum, F., 1982a. Temporal profile of neuronal damage in a model of transient forebrain ischemia. Ann. Neurol. 11, 491-498.

Pulsinelli, W.A., Levy, D.E., Duffy, T.E., 1982b. Regional cerebral blood flow and glucose metabolism following transient forebrain ischemia. Ann. Neurol. 11, 499-502. 
Puram, S.V., Kim, A.H., Park, H.Y., Anckar, J., Bonni, A., 2013. The ubiquitin receptor S5a/Rpn10 links centrosomal proteasomes with dendrite development in the mammalian brain. Cell Rep. 4, 19-30.

Qiu, J.H., Asai, A., Chi, S., Saito, N., Hamada, H., Kirino, T., 2000. Proteasome inhibitors induce cytochrome c-caspase-3-like protease-mediated apoptosis in cultured cortical neurons. J. Neurosci. 20, 259-265.

Rehni, A.K., Singh, T.G., Behl, N., Arora, S., 2010. Possible involvement of ubiquitin proteasome system and other proteases in acute and delayed aspects of ischemic preconditioning of brain in mice. Biol. Pharm. Bull. 33, 19531957.

Reinheckel, T., Sitte, N., Ullrich, O., Kuckelkorn, U., Davies, K.J., Grune, T., 1998. Comparative resistance of the 20S and 26S proteasome to oxidative stress. Biochem. J. 335 (Pt 3) 637-642.

Reits, E.A., Benham, A.M., Plougastel, B., Neefjes, J., Trowsdale, J., 1997. Dynamics of proteasome distribution in living cells. EMBO J. 16, 6087-6094.

Roberts, G.G., Di Loreto, M.J., Marshall, M., Wang, J., DeGracia, D.J., 2007. Hippocampal cellular stress responses after global brain ischemia and reperfusion. Antioxid. Redox Signal. 9, 2265-2275.

Rock, K.L., Gramm, C., Rothstein, L., Clark, K., Stein, R., Dick, L., Hwang, D., Goldberg, A.L., 1994. Inhibitors of the proteasome block the degradation of most cell proteins and the generation of peptides presented on MHC class I molecules. Cell 78, 761-771.

Roger, V.L., Go, A.S., Lloyd-Jones, D.M., Benjamin, E.J., Berry, J.D., Borden, W.B. Bravata, D.M., Dai, S., Ford, E.S., Fox, C.S., Fullerton, H.J., Gillespie, C., Hailpern, S.M., Heit, J.A., Howard, V.J., Kissela, B.M., Kittner, S.J., Lackland, D.T., Lichtman, J.H., Lisabeth, L.D., Makuc, D.M., Marcus, G.M., Marelli, A., Matchar, D.B., Moy, C.S., Mozaffarian, D., Mussolino, M.E., Nichol, G., Paynter, N.P., Soliman, E.Z., Sorlie, P.D., Sotoodehnia, N., Turan, T.N., Virani, S.S., Wong, N.D., Woo, D., Turner, M.B., 2012. Heart disease and stroke statistics-2012 update: a report from the American Heart Association. Circulation 125, e2-e220.

Rong, Y., Lu, X., Bernard, A., Khrestchatisky, M., Baudry, M., 2001. Tyrosine phosphorylation of ionotropic glutamate receptors by Fyn or Src differentially modulates their susceptibility to calpain and enhances their binding to spectrin and PSD-95. J. Neurochem. 79, 382-390.

Rosenzweig, R., Bronner, V., Zhang, D., Fushman, D., Glickman, M.H., 2012. Rpn1 and Rpn2 coordinate ubiquitin processing factors at proteasome. J. Biol. Chem. 287, 14659-14671.

Rossi, D.J., Oshima, T., Attwell, D., 2000. Glutamate release in severe brain ischaemia is mainly by reversed uptake. Nature 403, 316-321.

Roy, S., Sharom, J.R., Houde, C., Loisel, T.P., Vaillancourt, J.P., Shao, W., Saleh, M., Nicholson, D.W., 2008. Confinement of caspase-12 proteolytic activity to autoprocessing. Proc. Natl. Acad. Sci. U.S.A. 105, 4133-4138.

Ruschak, A.M., Slassi, M., Kay, L.E., Schimmer, A.D., 2011. Novel proteasome inhibitors to overcome bortezomib resistance. J. Natl. Cancer Inst. 103, 1007-1017.

Russell, S.J., Steger, K.A., Johnston, S.A., 1999. Subcellular localization, stoichiometry, and protein levels of $26 \mathrm{~S}$ proteasome subunits in yeast. J. Biol. Chem. 274, 21943-21952.

Sakata, E., Bohn, S., Mihalache, O., Kiss, P., Beck, F., Nagy, I., Nickell, S., Tanaka, K., Saeki, Y., Forster, F., Baumeister, W., 2012. Localization of the proteasomal ubiquitin receptors Rpn10 and Rpn13 by electron cryomicroscopy. Proc. Natl. Acad. Sci. U.S.A. 109, 1479-1484.

Sanchez-Gomez, M.V., Alberdi, E., Perez-Navarro, E., Alberch, J., Matute, C., 2011. Bax and calpain mediate excitotoxic oligodendrocyte death induced by activation of both AMPA and kainate receptors. J. Neurosci. 31, 2996-3006.

Sattler, R., Tymianski, M., 2000. Molecular mechanisms of calcium-dependent excitotoxicity. J. Mol. Med. (Berl.) 78, 3-13.

Schlesinger, D.H., Goldstein, G., Niall, H.D., 1975. The complete amino acid sequence of ubiquitin, an adenylate cyclase stimulating polypeptide probably universal in living cells. Biochemistry 14, 2214-2218.

Schreiner, P., Chen, X., Husnjak, K., Randles, L., Zhang, N.X., Elsasser, S., Finley, D., Dikic, I., Walters, K.J., Groll, M., 2008. Ubiquitin docking at the proteasome through a novel pleckstrin-homology domain interaction. Nature 453, 548552.

Schubert, U., Anton, L.C., Gibbs, J., Norbury, C.C., Yewdell, J.W., Bennink, J.R., 2000 Rapid degradation of a large fraction of newly synthesized proteins by proteasomes. Nature 404, 770-774

Schwarz, L.A., Hall, B.J., Patrick, G.N., 2010. Activity-dependent ubiquitination of GluA1 mediates a distinct AMPA receptor endocytosis and sorting pathway. J. Neurosci. 30, 16718-16729.

Seibenhener, M.L., Babu, J.R., Geetha, T., Wong, H.C., Krishna, N.R., Wooten, M.W., 2004. Sequestosome 1 /p62 is a polyubiquitin chain binding protein involved in ubiquitin proteasome degradation. Mol. Cell. Biol. 24, 8055-8068.

Seyfried, D.M., Veyna, R., Han, Y., Li, K., Tang, N., Betts, R.L., Weinsheimer, S., Chopp, M., Anagli, J., 2001. A selective cysteine protease inhibitor is non-toxic and cerebroprotective in rats undergoing transient middle cerebral artery ischemia. Brain Res. 901, 94-101.

Shabek, N., Herman-Bachinsky, Y., Buchsbaum, S., Lewinson, O., Haj-Yahya, M., Hejjaoui, M., Lashuel, H.A., Sommer, T., Brik, A., Ciechanover, A., 2012. The size of the proteasomal substrate determines whether its degradation will be mediated by mono- or polyubiquitylation. Mol. Cell 48, 87-97.

Sheardown, M.J., Nielsen, E.O., Hansen, A.J., Jacobsen, P., Honore, T., 1990. 2,3Dihydroxy-6-nitro-7-sulfamoyl-benzo(F)quinoxaline: a neuroprotectant for cerebral ischemia. Science 247, 571-574.

Sheng, R., Liu, X.Q., Zhang, L.S., Gao, B., Han, R., Wu, Y.Q., Zhang, X.Y., Qin, Z.H., 2012. Autophagy regulates endoplasmic reticulum stress in ischemic preconditioning. Autophagy $8,310-325$.
Shibata, M., Hattori, H., Sasaki, T., Gotoh, J., Hamada, J., Fukuuchi, Y., 2003. Activation of caspase- 12 by endoplasmic reticulum stress induced by transient middle cerebral artery occlusion in mice. Neuroscience 118, 491-499.

Shih, A.Y., Blinder, P., Tsai, P.S., Friedman, B., Stanley, G., Lyden, P.D., Kleinfeld, D. 2013. The smallest stroke: occlusion of one penetrating vessel leads to infarction and a cognitive deficit. Nat. Neurosci. 16, 55-63.

Shin, S.M., Zhang, N., Hansen, J., Gerges, N.Z., Pak, D.T., Sheng, M., Lee, S.H., 2012. GKAP orchestrates activity-dependent postsynaptic protein remodeling and homeostatic scaling. Nat. Neurosci. 15, 1655-1666.

Simon, R.P., Swan, J.H., Griffiths, T., Meldrum, B.S., 1984. Blockade of N-methyl-Daspartate receptors may protect against ischemic damage in the brain. Science $226,850-852$

Soundarapandian, M.M., Tu, W.H., Peng, P.L., Zervos, A.S., Lu, Y., 2005. AMPA receptor subunit GluR2 gates injurious signals in ischemic stroke. Mol. Neurobiol. 32, 145-155.

Stanika, R.I., Pivovarova, N.B., Brantner, C.A., Watts, C.A., Winters, C.A., Andrews, S.B 2009. Coupling diverse routes of calcium entry to mitochondrial dysfunction and glutamate excitotoxicity. Proc. Natl. Acad. Sci. U.S.A. 106, 9854-9859.

Stoehr, G., Schaab, C., Graumann, J., Mann, M., 2013. A SILAC-based approach identifies substrates of caspase-dependent cleavage upon TRAIL-induced apoptosis. Mol. Cell. Proteomics 12, 1436-1450.

Sun, H.S., Jackson, M.F., Martin, L.J., Jansen, K., Teves, L., Cui, H., Kiyonaka, S., Mori, Y. Jones, M., Forder, J.P., Golde, T.E., Orser, B.A., Macdonald, J.F., Tymianski, M. 2009. Suppression of hippocampal TRPM7 protein prevents delayed neuronal death in brain ischemia. Nat. Neurosci. 12, 1300-1307.

Sun, X.M., Butterworth, M., MacFarlane, M., Dubiel, W., Ciechanover, A., Cohen, G.M. 2004. Caspase activation inhibits proteasome function during apoptosis. Mol. Cell 14, 81-93.

Taglialatela, G., Kaufmann, J.A., Trevino, A., Perez-Polo, J.R., 1998. Central nervous system DNA fragmentation induced by the inhibition of nuclear factor kappa B. Neuroreport 9, 489-493.

Tai, H.C., Besche, H., Goldberg, A.L., Schuman, E.M., 2010. Characterization of the Brain 26S Proteasome and its Interacting Proteins. Front. Mol. Neurosci. 3, 12

Tajiri, S., Oyadomari, S., Yano, S., Morioka, M., Gotoh, T., Hamada, J.I., Ushio, Y., Mori, M., 2004. Ischemia-induced neuronal cell death is mediated by the endoplasmic reticulum stress pathway involving CHOP. Cell Death Differ. 11, 403-415.

Takano, J., Tomioka, M., Tsubuki, S., Higuchi, M., Iwata, N., Itohara, S., Maki, M., Saido, T.C., 2005. Calpain mediates excitotoxic DNA fragmentation via mitochondrial pathways in adult brains: evidence from calpastatin mutant mice. J. Biol. Chem. 280, 16175-16184.

Tan, Y.Y., Zhou, H.Y., Wang, Z.Q., Chen, S.D., 2008. Endoplasmic reticulum stress contributes to the cell death induced by UCH-L1 inhibitor. Mol. Cell. Biochem. $318,109-115$.

Tanaka, H., Grooms, S.Y., Bennett, M.V., Zukin, R.S., 2000. The AMPAR subunit GluR2: still front and center-stage. Brain Res. 886, 190-207.

Tanaka, K., Yoshimura, T., Tamura, T., Fujiwara, T., Kumatori, A., Ichihara, A., 1990 Possible mechanism of nuclear translocation of proteasomes. FEBS Lett. 271, 41-46.

Todi, S.V., Paulson, H.L., 2011. Balancing act: deubiquitinating enzymes in the nervous system. Trends Neurosci. 34, 370-382.

Tomko Jr., R.J., Hochstrasser, M., 2013. Molecular architecture and assembly of the eukaryotic proteasome. Annu. Rev. Biochem. 82, 415-445.

Truettner, J.S., Hu, K., Liu, C.L., Dietrich, W.D., Hu, B., 2009. Subcellular stress response and induction of molecular chaperones and folding proteins after transient global ischemia in rats. Brain Res. 1249, 9-18.

Tsai, N.P., Wilkerson, J.R., Guo, W., Maksimova, M.A., Demartino, G.N., Cowan, C.W. Huber, K.M., 2012. Multiple Autism-linked genes mediate synapse elimination via proteasomal degradation of a synaptic scaffold PSD-95. Cell 151, 15811594.

Urban, P., Pavlikova, M., Sivonova, M., Kaplan, P., Tatarkova, Z., Kaminska, B. Lehotsky, J., 2009. Molecular analysis of endoplasmic reticulum stress response after global forebrain ischemia/reperfusion in rats: effect of neuroprotectant simvastatin. Cell Mol. Neurobiol. 29, 181-192.

Vadhvani, M., Schwedhelm-Domeyer, N., Mukherjee, C., Stegmuller, J., 2013. The centrosomal E3 ubiquitin ligase FBXO31-SCF regulates neuronal morphogenesis and migration. PLoS One 8, e57530.

van Den Hurk, W.H., Willems, H.J., Bloemen, M., Martens, G.J., 2001. Novel frameshift mutations near short simple repeats. J. Biol. Chem. 276, 11496-11498.

van Deventer, S., Neefjes, J., 2010. The immunoproteasome cleans up after inflammation. Cell 142, 517-518.

von Mikecz, A., 2006. The nuclear ubiquitin-proteasome system. J. Cell Sci. 119, 1977-1984.

Waataja, J.J., Kim, H.J., Roloff, A.M., Thayer, S.A., 2008. Excitotoxic loss of postsynaptic sites is distinct temporally and mechanistically from neuronal death. J. Neurochem. 104, 364-375.

Wada, M., Kosaka, M., Saito, S., Sano, T., Tanaka, K., Ichihara, A., 1993. Serum concentration and localization in tumor cells of proteasomes in patients with hematologic malignancy and their pathophysiologic significance. J. Lab. Clin. Med. 121, 215-223.

Wagner, S.A., Beli, P., Weinert, B.T., Nielsen, M.L., Cox, J., Mann, M., Choudhary, C. 2011. A proteome-wide, quantitative survey of in vivo ubiquitylation sites reveals widespread regulatory roles. Mol. Cell. Proteomics 10, M111 013284.

Walters, B.J., Campbell, S.L., Chen, P.C., Taylor, A.P., Schroeder, D.G., Dobrunz, L.E. Artavanis-Tsakonas, K., Ploegh, H.L., Wilson, J.A., Cox, G.A., Wilson, S.M., 2008. Differential effects of Usp14 and Uch-L1 on the ubiquitin proteasome system and synaptic activity. Mol. Cell. Neurosci. 39, 539-548. 
Wang, F., Durfee, L.A., Huibregtse, J.M., 2013. A cotranslational ubiquitination pathway for quality control of misfolded proteins. Mol. Cell 50, 368-378.

Waung, M.W., Pfeiffer, B.E., Nosyreva, E.D., Ronesi, J.A., Huber, K.M., 2008. Rapid translation of Arc/Arg3.1 selectively mediates mGluR-dependent LTD through persistent increases in AMPAR endocytosis rate. Neuron 59, 84-97.

Wei, G., Yin, Y., Li, W., Bito, H., She, H., Mao, Z., 2012. Calpain-mediated degradation of myocyte enhancer factor 2D contributes to excitotoxicity by activation of extrasynaptic N-methyl-D-aspartate receptors. J. Biol. Chem. 287, 5797-5805.

Weih, M., Schmitt, M., Gieche, J., Harms, C., Ruscher, K., Dirnagl, U., Grune, T., 2001. Proteolysis of oxidized proteins after oxygen-glucose deprivation in rat cortical neurons is mediated by the proteasome. J. Cereb. Blood Flow Metab. 21, 10901096.

Wickliffe, K.E., Williamson, A., Meyer, H.J., Kelly, A., Rape, M., 2011. K11-linked ubiquitin chains as novel regulators of cell division. Trends Cell Biol. 21, 656663.

Wigley, W.C., Fabunmi, R.P., Lee, M.G., Marino, C.R., Muallem, S., DeMartino, G.N., Thomas, P.J., 1999. Dynamic association of proteasomal machinery with the centrosome. J. Cell Biol. 145, 481-490.

Wilkinson, K.D., Urban, M.K., Haas, A.L., 1980. Ubiquitin is the ATP-dependent proteolysis factor I of rabbit reticulocytes. J. Biol. Chem. 255, 7529-7532.

Willeumier, K., Pulst, S.M., Schweizer, F.E., 2006. Proteasome inhibition triggers activity-dependent increase in the size of the recycling vesicle pool in cultured hippocampal neurons. J. Neurosci. 26, 11333-11341.

Williams, A.J., Berti, R., Dave, J.R., Elliot, P.J., Adams, J., Tortella, F.C., 2004. Delayed treatment of ischemia/reperfusion brain injury: extended therapeutic window with the proteosome inhibitor MLN519. Stroke 35, 1186-1191.

Williams, A.J., Hale, S.L., Moffett, J.R., Dave, J.R., Elliott, P.J., Adams, J., Tortella, F.C. 2003. Delayed treatment with MLN519 reduces infarction and associated neurologic deficit caused by focal ischemic brain injury in rats via antiinflammatory mechanisms involving nuclear factor-kappaB activation, gliosis, and leukocyte infiltration. J. Cereb. Blood Flow Metab. 23, 75-87.

Williams, A.J., Myers, T.M., Cohn, S.I., Sharrow, K.M., Lu, X.C., Tortella, F.C., 2005 Recovery from ischemic brain injury in the rat following a $10 \mathrm{~h}$ delayed injection with MLN519. Pharmacol. Biochem. Behav. 81, 182-189.

Williams, C.A., Driscoll, D.J., Dagli, A.I., 2010. Clinical and genetic aspects of Angelman syndrome. Genet. Med. 12, 385-395.

Wilson, S.M., Bhattacharyya, B., Rachel, R.A., Coppola, V., Tessarollo, L., Householder D.B., Fletcher, C.F., Miller, R.J., Copeland, N.G., Jenkins, N.A., 2002. Synaptic defects in ataxia mice result from a mutation in Usp14, encoding a ubiquitinspecific protease. Nat. Genet. 32, 420-425.

Wroge, C.M., Hogins, J., Eisenman, L., Mennerick, S., 2012. Synaptic NMDA receptors mediate hypoxic excitotoxic death. J. Neurosci. 32, 6732-6742.

Xie, Y., 2010. Structure, assembly and homeostatic regulation of the $26 \mathrm{~S}$ proteasome. J. Mol. Cell. Biol. 2, 308-317.

Xiong, Z.G., Zhu, X.M., Chu, X.P., Minami, M., Hey, J., Wei, W.L., MacDonald, J.F., Wemmie, J.A., Price, M.P., Welsh, M.J., Simon, R.P., 2004. Neuroprotection in ischemia: blocking calcium-permeable acid-sensing ion channels. Cell 118 687-698.

Xu, J., Kurup, P., Zhang, Y., Goebel-Goody, S.M., Wu, P.H., Hawasli, A.H., Baum, M.L. Bibb, J.A., Lombroso, P.J., 2009a. Extrasynaptic NMDA receptors couple preferentially to excitotoxicity via calpain-mediated cleavage of STEP. J. Neurosci. 29, 9330-9343.

Xu, P., Duong, D.M., Seyfried, N.T., Cheng, D., Xie, Y., Robert, J., Rush, J., Hochstrasser, M., Finley, D., Peng, J., 2009b. Quantitative proteomics reveals the function of unconventional ubiquitin chains in proteasomal degradation. Cell 137, 133145 .

Yamashiro, K., Liu, R., Maeda, M., Hattori, N., Urabe, T., 2007. Induction and selective accumulation of mutant ubiquitin in CA1 pyramidal neurons after transient global ischemia. Neuroscience 147, 71-79.

Yang, S.W., Oh, K.H., Park, E., Chang, H.M., Park, J.M., Seong, M.W., Ka, S.H., Song, W.K., Park, D.E., Baas, P.W., Jeon, Y.J., Chung, C.H., 2013. USP47 and C terminus of Hsp70-interacting protein (CHIP) antagonistically regulate katanin-p60-mediated axonal growth. J. Neurosci. 33, 12728-12738.

Yang, Z., Klionsky, D.J., 2009. An overview of the molecular mechanism of autophagy. Curr. Top. Microbiol. Immunol. 335, 1-32.

Ye, Y., Rape, M., 2009. Building ubiquitin chains: E2 enzymes at work. Nat. Rev. Mol. Cell. Biol. 10, 755-764.

Ye, Z.C., Wyeth, M.S., Baltan-Tekkok, S., Ransom, B.R., 2003. Functional hemichannels in astrocytes: a novel mechanism of glutamate release. J. Neurosci. 23, 3588-3596.

Yi, J.J., Ehlers, M.D., 2007. Emerging roles for ubiquitin and protein degradation in neuronal function. Pharmacol. Rev. 59, 14-39.

Yoshida, H., Haze, K., Yanagi, H., Yura, T., Mori, K., 1998. Identification of the cisacting endoplasmic reticulum stress response element responsible for transcriptional induction of mammalian glucose-regulated proteins. Involvement of basic leucine zipper transcription factors. J. Biol. Chem. 273, 33741-33749.

Yuen, E.Y., Liu, W., Yan, Z., 2007. The phosphorylation state of GluR1 subunits determines the susceptibility of AMPA receptors to calpain cleavage. J. Biol. Chem. 282, 16434-16440.

Zhang, F., Liu, C.L., Hu, B.R., 2006a. Irreversible aggregation of protein synthesis machinery after focal brain ischemia. J. Neurochem. 98, 102-112.

Zhang, L., Zhang, Z.G., Buller, B., Jiang, J., Jiang, Y., Zhao, D., Liu, X., Morris, D., Chopp, M., 2010. Combination treatment with VELCADE and low-dose tissue plasminogen activator provides potent neuroprotection in aged rats after embolic focal ischemia. Stroke 41, 1001-1007

Zhang, L., Zhang, Z.G., Liu, X., Hozeska, A., Stagliano, N., Riordan, W., Lu, M., Chopp, M., 2006b. Treatment of embolic stroke in rats with bortezomib and recombinant human tissue plasminogen activator. Thromb. Haemost. 95, 166-173.

Zhang, L., Zhang, Z.G., Zhang, R.L., Lu, M., Adams, J., Elliott, P.J., Chopp, M., 2001. Postischemic (6-Hour) treatment with recombinant human tissue plasminogen activator and proteasome inhibitor PS-519 reduces infarction in a rat model of embolic focal cerebral ischemia. Stroke 32, 2926-2931.

Zhang, Q.G., Xu, Y.L., Li, H.C., Han, D., Zhang, G.Y., 2006c. NMDA receptor/L-VGCCdependent expression and AMPA/KA receptor-dependent activation of c-Jun induced by cerebral ischemia in rat hippocampus. Neurosci. Lett. 398, 268-273.

Zhang, X., Yan, H., Yuan, Y., Gao, J., Shen, Z., Cheng, Y., Shen, Y., Wang, R.R., Wang, X., Hu, W.W., Wang, G., Chen, Z., 2013a. Cerebral ischemia-reperfusion-induced autophagy protects against neuronal injury by mitochondrial clearance. Autophagy $9,1321-1333$.

Zhang, Y., Zhou, L., Rouge, L., Phillips, A.H., Lam, C., Liu, P., Sandoval, W., Helgason, E., Murray, J.M., Wertz, I.E., Corn, J.E., 2013b. Conformational stabilization of ubiquitin yields potent and selective inhibitors of USP7. Nat. Chem. Biol. 9, 51-58.

Ziv, I., Matiuhin, Y., Kirkpatrick, D.S., Erpapazoglou, Z., Leon, S., Pantazopoulou, M., Kim, W., Gygi, S.P., Haguenauer-Tsapis, R., Reis, N., Glickman, M.H., Kleifeld, O., 2011. A perturbed ubiquitin landscape distinguishes between ubiquitin in trafficking and in proteolysis. Mol. Cell. Proteomics 10, M111 009753. 